\title{
Characterization of local and global capacity criteria for collapse assessment of code-conforming RC buildings
}

\author{
Danilo D'Angela ${ }^{1}$ (D) Gennaro Magliulo ${ }^{1,2}$ [D $\cdot$ Francesca Celano ${ }^{3}$. \\ Edoardo Cosenza ${ }^{1,2}$ (D)
}

Received: 4 February 2021 / Accepted: 27 April 2021 / Published online: 19 May 2021

(c) The Author(s) 2021

\begin{abstract}
The paper investigates both local and global capacity criteria for collapse assessment of RC frame buildings. Both literature and regulations criteria are considered, also including the formulation recommended in the draft of the new Eurocode 8 (part 3) and other collapse criteria never investigated. The case studies consist of low-rise bare and infilled frame buildings, which are designed according to the Italian code provisions considering low-to-high seismicity sites in Italy. The seismic demand is estimated by performing multiple-stripe analysis based on inelastic modeling, also including the presence of the infills. The capacity assessment and the performance evaluation associated with the (building) collapse are carried out according to the latest approaches and methodologies of performance-based earthquake engineering. The investigated capacity criteria are characterized as a result of the collapse assessment in terms of (a) collapse demand to capacity ratios, (b) collapse fragility curves, (c) collapse margin ratios and probabilities, and (d) inter-capacity margin ratios. The findings provide novel information and technical insights into the influence of the collapse capacity criteria selection on the collapse features of the investigated buildings. In particular, the capacity criteria are quantitatively correlated to the building collapse performance, also outlining safety and economic considerations.
\end{abstract}

Keywords Collapse $\cdot$ Capacity criteria $\cdot$ RC buildings $\cdot$ Seismic assessment $\cdot$ Fragility . Collapse performance

\section{List of symbols}

$\mathrm{a}_{\mathrm{g}} \quad$ Design acceleration at bedrock

$\mathrm{a}_{\mathrm{s}} \quad$ Capping to yielding moment ratio

$\mathrm{a}_{\mathrm{sl}} \quad$ Bond-slip indicator variable from Haselton and Deierlein (2007)

$\mathrm{a}_{\mathrm{v}} \mathrm{z} \quad$ Tension shift of the bending moment diagram

$\bar{a} \quad$ Ground floor total column area to the total floor area ratio

c Hysteretic degradation parameter

D Asymmetric hysteretic degradation rate

D/C Demand to capacity ratio

Gennaro Magliulo gmagliul@unina.it

Extended author information available on the last page of the article 


\begin{tabular}{|c|c|}
\hline$d_{p}$ & Infill equivalent strut length \\
\hline$d_{b L}$ & Lapped bars diameter \\
\hline e & Infill panel thickness \\
\hline $\mathrm{EI}_{\mathrm{y}}$ & Secant to yield elastic flexural stiffness \\
\hline $\mathrm{E}_{\mathrm{c}}$ & Concrete elastic modulus \\
\hline $\mathrm{E}_{\mathrm{m}}$ & Infill equivalent elastic modulus \\
\hline edp & Specific value of an engineering demand parameter EDP \\
\hline$f_{c}$ & Mean concrete compressive strength \\
\hline$f_{y}$ & Mean longitudinal reinforcement steel yielding strength \\
\hline$f_{y w}$ & Mean stirrup steel yielding strength \\
\hline$f_{\text {sr }}$ & Infill equivalent strut joint sliding strength \\
\hline $\mathrm{h}$ & Centerline story height \\
\hline $\mathrm{H}$ & Cross-section depth \\
\hline $\mathrm{H}_{\mathrm{m}}$ & Infill equivalent strut lateral shear force \\
\hline $\mathrm{H}_{\mathrm{mfc}}$ & Infill equivalent strut peak lateral shear force from Decanini et al. (2004) \\
\hline $\mathrm{H}_{\mathrm{mf}}$ & Infill equivalent strut cracking lateral shear force \\
\hline $\mathrm{H}_{\mathrm{mr}}$ & Infill equivalent strut residual lateral shear force \\
\hline$h_{p}$ & Infill panel height \\
\hline $\mathrm{h}_{0}$ & Infill opening vertical dimension \\
\hline I & Column inertia moment \\
\hline IDR & Inter-story drift ratio \\
\hline $\mathrm{IDR}_{\mathrm{u}}$ & Inter-story drift ratio collapse capacity \\
\hline $\mathrm{IDR}_{\mathrm{u} 1}$ & $\begin{array}{l}\text { Inter-story drift ratio collapse capacity from FEMA } 356 \text { (Federal Emergency } \\
\text { Management Agency (FEMA) 2009) }\end{array}$ \\
\hline $\mathrm{IDR}_{\mathrm{u} 2}$ & Inter-story drift ratio collapse capacity from Ghobarah (2004) \\
\hline $\mathrm{IDR}_{\mathrm{u} 3}$ & $\begin{array}{l}\text { Inter-story drift ratio collapse capacity from ASCE 7-16 (American Society } \\
\text { of Civil Engineers 2017b) and also used by Rajeev and Tesfamariam (2012) }\end{array}$ \\
\hline $\mathrm{IDR}_{\mathrm{u} 4}$ & Inter-story drift ratio collapse capacity from Di Trapani et al. (2020) \\
\hline $\mathrm{IDR}_{\mathrm{u} 5}$ & $\begin{array}{l}\text { Inter-story drift ratio collapse capacity from FEMA P695 (Federal Emer- } \\
\text { gency Management Agency (FEMA) 2009) and (Gokkaya et al. 2016; } \\
\text { O'Reilly and Sullivan 2018; Pourreza et al. 2021) }\end{array}$ \\
\hline $\mathrm{K}_{\mathrm{mfc}}$ & Infill equivalent strut secant stiffness \\
\hline $\mathrm{K}_{0}$ & Effective elastic stiffness \\
\hline $\mathrm{K}_{1}, \mathrm{~K}_{2}$ & Experimental constants from Decanini et al. (2004) \\
\hline $\mathrm{L}_{\mathrm{pl}}$ & Plastic hinge length \\
\hline $\mathrm{L}_{\mathrm{V}}$ & Shear span, i.e., end section moment to shear ratio \\
\hline 1 & Infill panel width \\
\hline $1_{\mathrm{p}}$ & Centerline column-to-column bay width \\
\hline $\mathrm{l}_{0}$ & Infill opening longitudinal dimension \\
\hline $\mathrm{m}$ & Fragility median value \\
\hline M & Moment \\
\hline $\mathrm{M}_{\mathrm{c}}$ & Capping moment \\
\hline$M_{r}$ & Residual moment \\
\hline $\mathrm{M}_{\mathrm{y}}$ & Yielding moment \\
\hline$m_{X}$ & Fragility median value related to $\mathrm{X}$ capacity criterion \\
\hline $\mathrm{m}_{\mathrm{Y}}$ & Fragility median value related to Y capacity criterion \\
\hline $\mathrm{N}_{\mathrm{CT}}$ & $\begin{array}{l}\text { Total number of collapse occurrences out of } 20 \text { pairs of records considering } \\
\text { all element types together }\end{array}$ \\
\hline
\end{tabular}




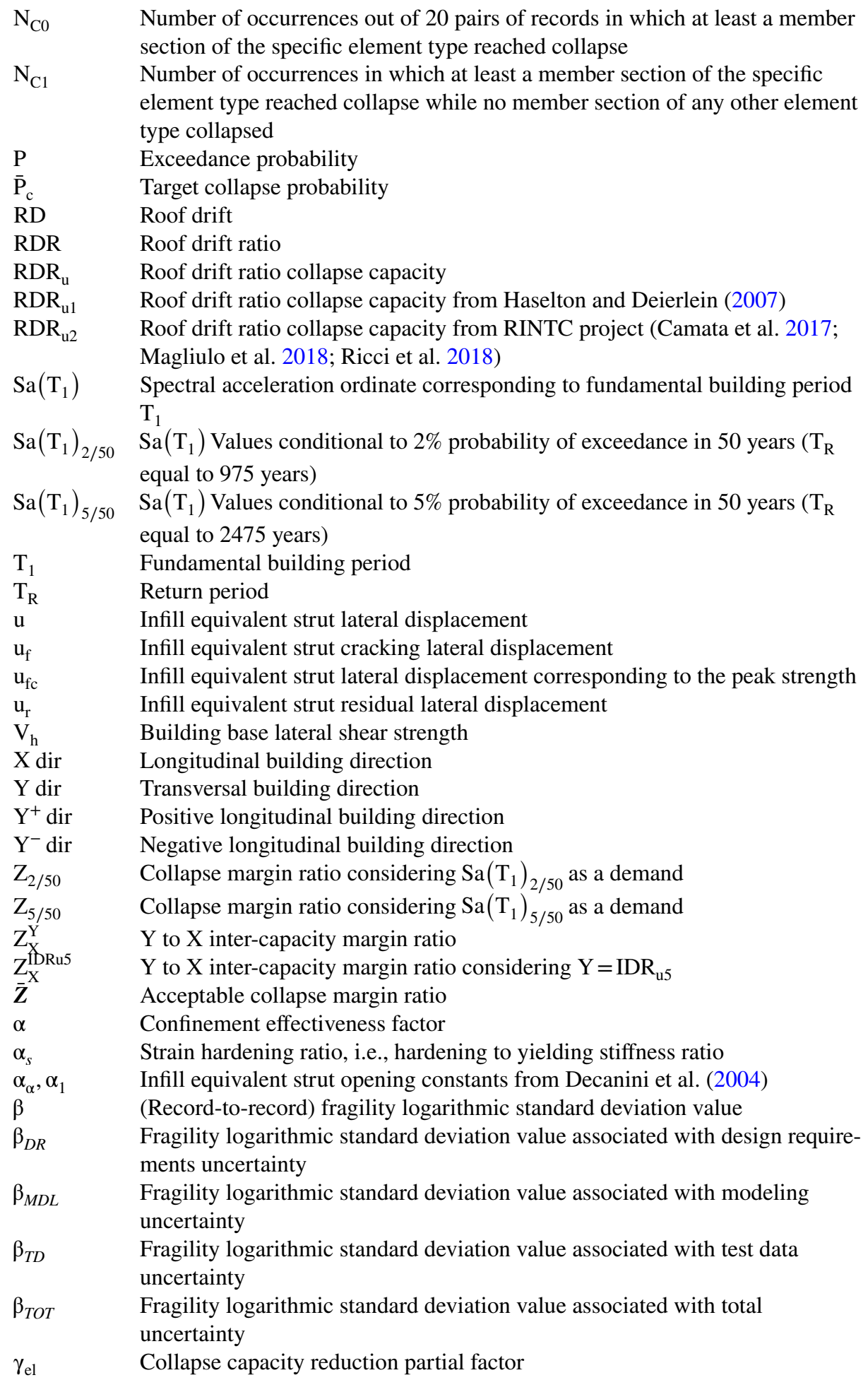




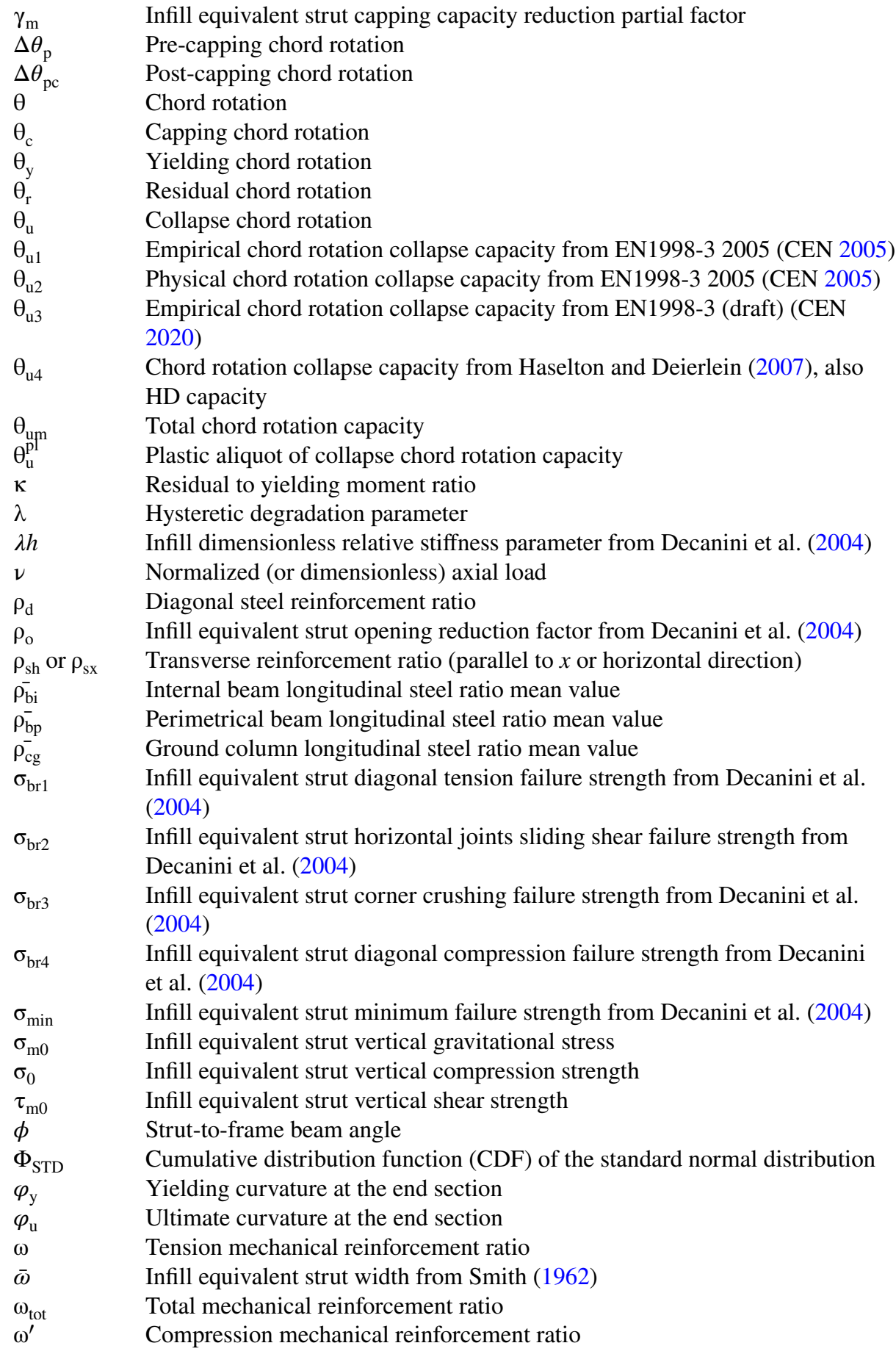




\section{Introduction}

The definition of the capacity criteria for collapse assessment of buildings is not a trivial issue (e.g., Deniz et al. 2017; Terrenzi et al. 2018). With regard to reinforced concrete (RC) buildings, several studies addressed this problem by developing a variety of collapse criteria based on physical and mechanical-empirical aspects or deterministic assumptions. The seminal work by Mwafy and Elnashai (2001) defined local and global criteria for collapse assessment of RC buildings. Local criteria are based on section flexural and shear failure, whereas three global criteria are defined by inter-story drift ratio (IDR) thresholds, sidesway collapse, and reduction in lateral strength of the pushover (PO) curve. The flexural failure was associated with the ultimate section chord rotation $\theta_{u}$, whereas the shear failure with the ultimate shear force/strength. The sidesway condition was quantitatively defined by the pioneering work of Vamvatsikos and Cornell (2002) as the onset of the (sub-)horizontal branch of the incremental dynamic analysis (IDA) curve, i.e., when a minor increase in terms of intensity measure (IM), e.g., spectral acceleration at the fundamental period $\left(S a\left(T_{1}\right)\right)$, determines a particularly significant deformation, e.g., roof drift ratio (RDR) increase. This criterion is typically used when IDAs are performed and the focus is on the condition of null lateral stiffness (Goulet et al. 2007). A more conservative condition was also suggested for the collapse prevention limit state by Vamvatsikos et al. (2003); this consisted in a reduction of $80 \%$ of the local stiffness of the IDA curve. The sidesway condition could also be referred to the building static behavior, e.g., to PO curves, which typically require a minor computational effort to be evaluated. In particular, the collapse corresponds to RDR associated with null shear strength (Vamvatsikos et al. 2003; Suita et al. 2008; Shafei et al. 2011). Analogously to the assumption related to the more conservative IDA-based collapse criterion [i.e., reduction in local stiffness of the IDA (Vamvatsikos et al. 2003)], a given strength reduction in the PO curve could define a collapse prevention limit state. As an example, $50 \%$ reduction in lateral shear strength of the PO curve was considered to define the collapse limit in recent studies (Camata et al. 2017; Magliulo et al. 2018; Ricci et al. 2018). A similar but more conservative criterion was already established by Haselton and Deierlein (2007), who defined the ultimate RDR as the ratio associated with a reduction of $20 \%$ in lateral shear strength of the PO curve.

Both local and global collapse criteria defined in the above-mentioned studies were adopted in several studies such as in Ghobarah (2004), Rossetto and Elnashai (2005), Haselton et al. (2009), and Baradan Shoraka et al. (2013). Regulations and codes often provide phenomenological criteria correlated to the qualitative response of the buildings to horizontal and vertical actions. Eurocode 8 (British Standards Institution and European Committee for Standardization 2005) establishes building performance criteria that indirectly imply the safety concerning collapse. Such criteria are based on resistance, ductility, and stability of the structural members/components. The quantitative collapse criteria supplied by the codes often refer to the local response of single members, e.g., shear strength for brittle mechanisms and chord rotation for ductile mechanisms (CEN 2005; CS.LL. PP. 2018). Therefore, the global collapse is implicitly associated with the earliest (shear or flexural) failure of members/components. This conventional condition is typically quite conservative for code-conforming buildings and far below the sidesway collapse. ASCE 7-16 (American Society of Civil Engineers 2017b) defines both global and local acceptance criteria in the framework of the nonlinear response assessment and also refers to ASCE 41 (American Society of Civil Engineers 2017a) for the collapse prevention specifications. The global criteria consist of (a) prevention of the unacceptable response and 
(b) assessment of IDR. The unacceptable response was defined by analytical instability or predicted demands significantly exceeding (modeling) capacities. The element-level (or local) acceptance criteria are defined considering both force- and deformation-controlled actions. Regarding local deformation-controlled mechanisms, ASCE 7-16 provides (a) a main criterion, referred to ASCE 41 (American Society of Civil Engineers 2017a), and (b) an alternative criterion based on the comparison of the mean inelastic deformation and an aliquot of the loss of gravity-load-carrying inelastic capacity, experimentally assessed. In particular, ASCE 41 (American Society of Civil Engineers 2017a) provides the formulations to evaluate (a) the plastic rotation at significant lateral force capacity (i.e., $20 \%$ or larger loss from the peak value) and (b) the plastic rotation at loss of gravity-load support. The associated acceptance criteria capacities are also supplied for collapse prevention building performance level. The reported formulations were derived from (Ghannoum and Sivaramakrishnan 2012; Ghannoum and Matamoros 2014).

A variety of empirical formulations for the chord rotation capacity at the collapse $\theta_{u}$ can be found in the literature, and the formulations developed by Biskinis and Fardis (2010a, b), as well as the ones recommended by EN1998-3:2005 (CEN 2005) and fib Model Code 2010 (MC 2010) (Beverly and International Federation for Structural Concrete 2013; Fardis 2013), are among the most referenced ones. Empirical formulations are also supplied in ASCE 41 (American Society of Civil Engineers 2017a), as previously mentioned. EN1998-3:2005 (CEN 2005) also supplies an alternative capacity formulation based on a physical approach, i.e., by assuming that the plastic part of the section curvature is uniform over a conventional length of the plastic hinge $\left(L_{p l}\right)$ (Ansal 2014). The draft of new EN1998-3 (CEN 2020) explicitly defines the collapse condition as a drop of moment equal to $20 \%$ of the capping value, according to the definition of Fardis and Biskinis (2003) and Haselton and Deierlein (2007). In this draft, the empirical formulation provided in the previous version is replaced by a novel one. Codes and guidelines such as FEMA P695 (Federal Emergency Management Agency (FEMA) 2009), FEMA 356 (Federal Emergency Management Agency (FEMA) 2000) and SEAOC Vision 2000 (Structural Engineers Association Of California (SEAOC) 1995) supply global capacity criteria based on building type-based IDR thresholds.

While several studies assessed the capacity models of RC members by comparing the capacity predictions with experimental results (Borg 2015; Fusco et al. 2018; Verderame and Ricci 2018), only few studies highlighted the significance of the selection of the criteria for the assessment of the collapse of RC buildings, especially for code-conforming buildings. Mpampatsikos et al. (2008) investigated the reliability of both Eurocode 8 (CEN 2005) and Italian seismic code OPCM 3431 (Presidente del Consiglio dei Ministri 2003, 2005) for the collapse assessment of irregular nonconforming RC buildings. They considered both empirical and physical formulations for $\theta_{u}$ provided in the reference codes. The extended study by Haselton et al. (2011) assessed the seismic risk of low-to-high rise bare frame RC buildings designed according to the US regulations by assuming sidesway collapse as a capacity criterion. Similarly, Noh and Tesfamariam (2018) evaluated the collapse risk related to low- and medium-rise bare and infilled frame RC buildings designed in compliance with the Canadian Standards (CSA 2014). Terrenzi et al. $(2018,2019)$ analyzed a medium- and high-rise code-conforming RC building. As collapse criteria, they considered the first achievement of the ultimate chord rotation $\theta_{u}$ (empirical formulation in EN19983 ), various IDR thresholds, and a reduction of $50 \%$ in lateral shear strength $V_{h}$ of the PO curve (Camata et al. 2017; Ricci et al. 2018). Di Trapani et al. (2020) carried out IDAs for the fragility and reliability assessment of a five-story code-conforming RC building. The collapse condition was defined as the lowest $\mathrm{IDR}_{\max }$ among the earliest achievement of (a) 
ultimate chord rotation of at least one column, (b) ultimate shear capacity of at least one column, and (c) IDR equal to $6.5 \%$. This latter criterion was associated with the projection of the top column centroid being located out of the base cross-section.

In the framework of the performance-based earthquake engineering (PBEE) approach, the different criteria are not only alternative collapse capacities, but they can also be meant as capacity criteria associated with the spectrum of collapse damage conditions. In other words, each criterion has a role within the holistic concept of the building response, and local and global criteria are expected to be somehow correlated among them. The assessment of the correlations between the local and global response highlights the qualities of the building design process. However, this issue has not been sufficiently assessed, to the authors' knowledge. If a building is conceived and designed according to the capacity design approach, such qualities should have distinctive characteristics, such as a significant lateral displacement margin between the heavily plastic behavior and the collapse, or a reduced margin between the earliest local collapse and the global one; furthermore, a global mechanism should be observed instead of a local one. Even though several studies assessed local and global collapse of frame RC buildings, no studies, to the knowledge of the authors, defined the relationships between the local and the global response of conforming buildings.

The present study covers the literature gap associated with the assessment of both local and global collapse capacity criteria related to code-conforming moment resisting frame (MRF) RC buildings. Two orders of aspects are investigated according to the PBEE approach: (1) collapse assessment of code-conforming low-rise RC frame buildings and (2) identification and quantification of the main features of the existing collapse criteria in terms of building response and seismic risk. The collapse assessment is performed by considering a wide variety of (local and global) collapse criteria as capacity measures (Sect. 2). The case studies consist of three-story bare frame (BF), infilled frame (IF), and pilotis frame (PF) buildings (Sect. 3). They are designed for three low-to-high seismicity sites in Italy according to the Italian building code NTC 2008 (CS.LL.PP. 2008) (Sect. 3). The seismic demand is evaluated by performing nonlinear multiple-stripe analysis (MSA) (Sect. 4). The characterization of local and global collapse capacity criteria (Sect. 5) is expressed in terms of (a) demand to capacity ratios, (b) fragility curves (collapse capacity assessment), (c) estimated and target collapse margin ratios and probabilities (collapse performance evaluation), and (d) inter-capacity margin ratios.

\section{Capacity criteria}

\subsection{Local and global criteria}

Both local and global engineering demand parameters (EDPs) were considered for the definition of the performance criteria, i.e., element section chord rotation $\theta$, inter-story drift ratio IDR, and roof drift ratio RDR. It is recalled that IDR can be expressed as the sum of the average beam and column $\theta$ of the story (e.g., Panagiotakos and Fardis 2004) and that, in the case of a building with the same story height, RDR is equal to the average of the building IDRs. The ultimate chord rotation capacities $\theta_{u}$ essentially depend on the characteristics of the members and their cross-sections. The IDR limits are typically fixed thresholds that might depend on the building typology or characteristics (e.g., Ghobarah 2004). The RDR capacities can be associated with a specific decrease in the building base 
shear strength $V_{h}$ of the PO curves (Camata et al. 2017; Ricci et al. 2018). Table 1 summarizes the investigated collapse capacity criteria, and it reports the essential formulation related to the case study applications. In particular, $\theta_{u 1}$ (Eq. 1) and $\theta_{u 2}$ (Eqs. 2.1, 2.2, and 2.3) are the empirical and the physical formulations recommended in EN1998-3:2005 (CEN 2005), whereas $\theta_{u 3}$ (Eqs. 3.1, 3.2, and 3.3) is the empirical capacity derived from the draft of new EN1998-3 (CEN 2020); $\theta_{u 4}$ (Eqs. 4.1, 4.2, 4.3, and 4.4) was developed by Haselton and Deierlein (2007); this latter is also referred to as HD capacity in the paper. $\mathrm{IDR}_{\mathrm{u} 1}$ (Eq. 5) was recommended by FEMA 356 (Federal Emergency Management Agency (FEMA) 2000) that also complies with FEMA 273 (Federal Emergency Management Agency (FEMA) 1997), $\operatorname{IDR}_{\mathrm{u} 2}$ (Eq. 6) was proposed by Ghobarah (2004), $\mathrm{IDR}_{\mathrm{u} 3}$ (Eq. 7) is recommended by ASCE 7-16 (American Society of Civil Engineers 2017b) and also used by Rajeev and Tesfamariam (2012), $\mathrm{IDR}_{\mathrm{u} 4}$ (Eq. 8) was developed by from Di Trapani et al. (2020), and $\operatorname{IDR}_{\mathrm{u} 5}$ (Eq. 9) was recommended by FEMA P695 (Federal Emergency Management Agency (FEMA) 2009) and corroborated in the literature. In particular, $\mathrm{IDR}_{\mathrm{u} 5}$ was found to be (a) well correlated to sidesway collapse or very reduced stiffness of most engineering structures (e.g., steel frames) (Vamvatsikos and Cornell 2002; Pourreza et al. 2021), (b) an upper bound collapse capacity estimate considering both ductile and nonductile RC buildings (Gokkaya et al. 2016), and (c) consistent with collapse of nonconforming Italian RC frame buildings by a sensitivity analysis performed by O'Reilly and Sullivan (2018). Therefore, in this study, this capacity is considered to be representative of reduced or null IDA slopes and relatively representative of sidesway collapse, with regard to the set of criteria investigated in this study.

The selected set of $\mathrm{IDR}_{\mathrm{u}}$ thresholds is representative of the whole range of potential significant IDR values and allows assessing the variability of this parameter in relation to the other ones. Furthermore, all $\mathrm{IDR}_{\mathrm{u}}$ criteria were derived from regulation and literature recommendations and, therefore, their use consideration is more than reasonable. $\mathrm{RDR}_{\mathrm{u} 1}$ (Eq. 10) was defined by Haselton and Deierlein (2007) as ultimate deformation capacity and $\mathrm{RDR}_{\mathrm{u} 2}$ (Eq. 11) was developed in the framework of RINTC project (Camata et al. 2017; RINTC Workgroup 2018; Magliulo et al. 2018; Ricci et al. 2018). The definition of the basic parameters used in Table 1 (Eqs. 1 to 11) is reported in the Notation section for the sake of brevity, whereas the main assumptions/specifications related to the present paper are reported in Sect. 2.2.

\subsection{Main assumptions and specifications}

The mean values were assumed for all mechanical parameters used for the computation of the capacities. For this purpose, the partial factor $\gamma_{e l}$ (Eqs. 1 and 2.1) was assumed equal to one (e.g., Borg 2015). The shear span $L_{v}$ (Eqs. 1, 2.1, 2.2, 2.3, 3.2, 3.3, and 4.2) was assumed to be equal to half story height in all cases (Mpampatsikos et al. 2008). A fiber analysis was implemented in MATLAB for the estimation of both yielding and ultimate curvatures $\varphi_{y}$ and $\varphi_{u}$ (Eqs. 2.1, 2.2, and 3.2). The yielding curvature $\varphi_{y}$ was evaluated by assuming the incipient yielding of the tension bars without taking into account the concrete confinement. The failure mechanisms to be assumed for the computation of the ultimate curvature $\varphi_{u}$ were selected according to the specific section equilibrium. Both concrete compression and steel tension failure conditions were considered by also including the concrete confinement. In particular, the provisions reported in EN 1992-1-1:2004 §3.1.9 (CEN 2004) were implemented for the definition of the confinement model, as well as the ultimate strain of the longitudinal reinforcement $\varepsilon_{s u}$ and effective lateral confining stress 


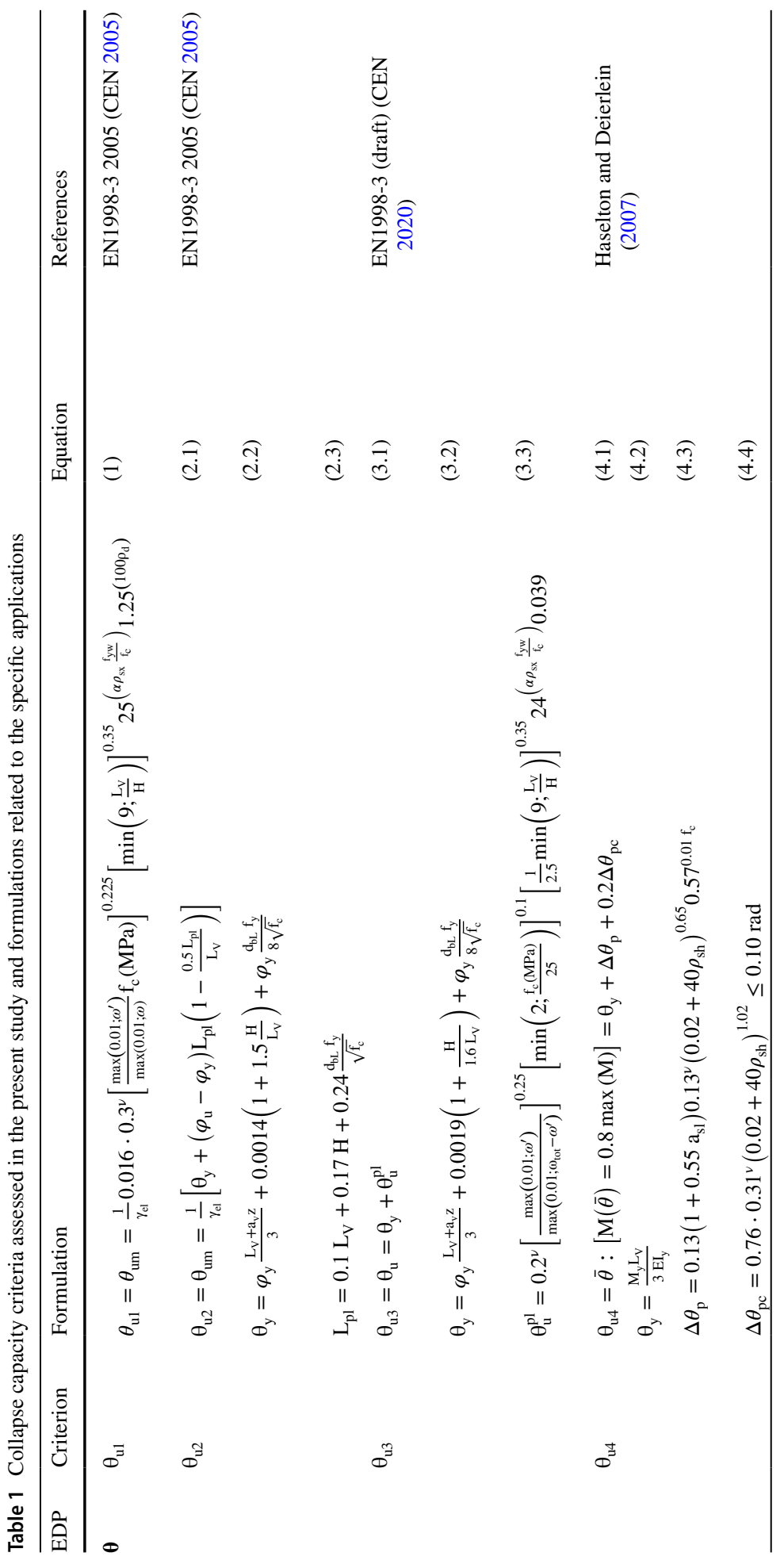




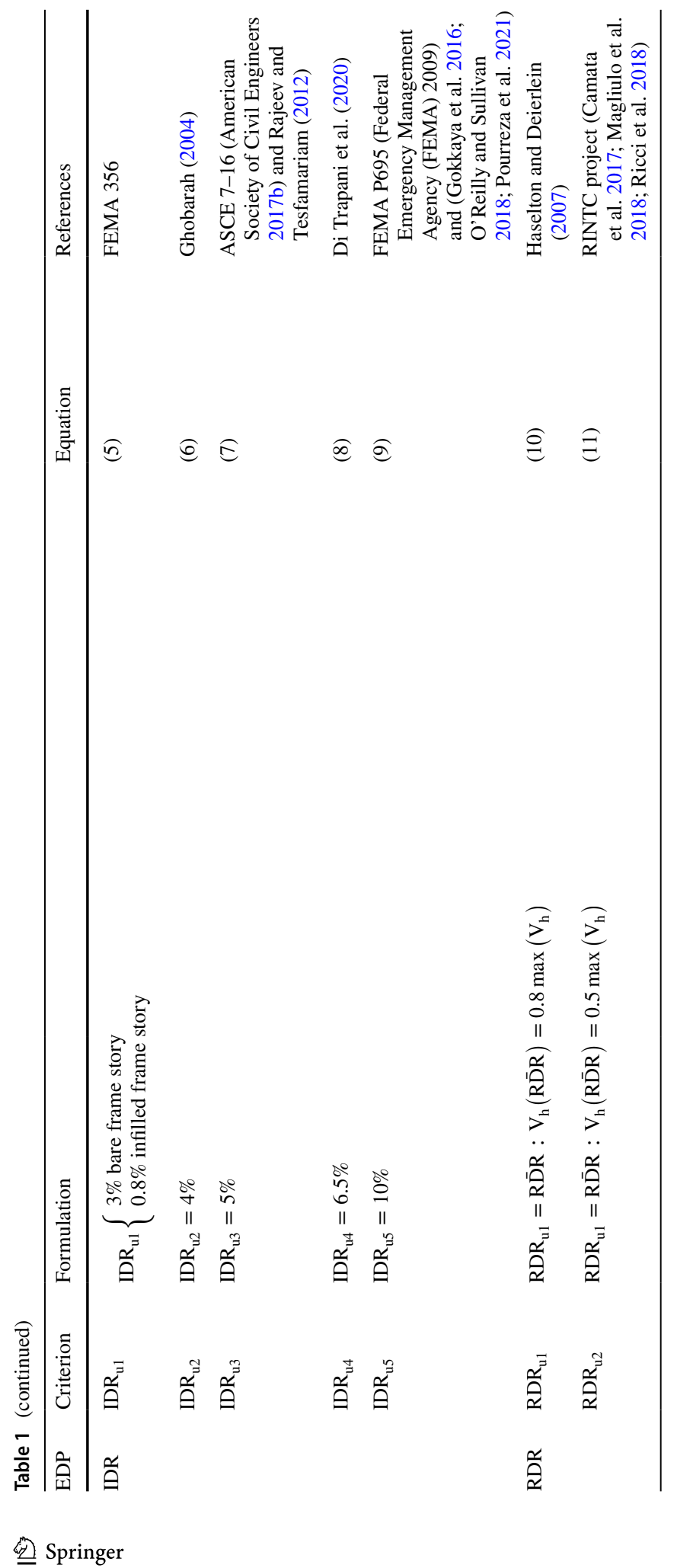


$\sigma_{2}$ were defined according to EN1998-3:2005 §A.3.2.2(7.a) and (7.b). Such conditions were compliant with the formulation used for the evaluation of the plastic hinge length $L_{p l}$ reported in formula A.5 in EN1998-3:2005 (Eq. 2.3).

Regarding the yielding chord rotation capacity $\theta_{y}$, it is worth noting that the draft of new EN1998-3 reports a formulation that is slightly different from the one recommended in the current version of the Eurocode. Therefore, $\theta_{y}$ was computed according to the new Eurocode draft provisions for the evaluation of $\theta_{u 3}$ (Eq. 3.2), whereas the current Eurocode formulation was considered for the computation of $\theta_{u 2}$ (Eq. 2.2). However, the different formulations supply very similar values, with differences that are negligible in all cases. Another clarification related to the draft of the new Eurocode is due. The physical capacity $\left(\theta_{u 2}\right)$ is considered to be an equivalent alternative to the empirical one $\left(\theta_{u 1}\right)$ within the current version of the Eurocode. Differently, the Eurocode draft recommends the empirical capacity $\left(\theta_{u 3}\right)$ for all cases in which the compression zone is rectangular and at right angles to the element web, e.g., the ordinary case of rectangular section, whereas the physical capacity $\left(\theta_{u 2}\right)$ is recommended for any other condition. $M_{y}$ was evaluated considering the formulation recommended by Haselton and Deierlein (2007) and developed by Panagiotakos and Fardis (2001), which is not reported in the manuscript for the sake of brevity.

\section{Case studies and building design}

Three-story residential MRF RC buildings were designed as ordinary buildings according to the Italian building code NTC 2008 (CS.LL.PP. 2008), which is compliant with Eurocode (British Standards Institution and European Committee for Standardization 2005). Figure 1 shows the (a) plan and (b) elevation layouts of the frames and (c) the typical architectural plan. BF, IF, and PF buildings were considered: IF has all bays infilled, whereas PF has bare ground floor bays and all other ones are infilled. Hollow clay brick panels having a thickness equal to $300 \mathrm{~mm}$ were considered as a representative system of typical Italian and Mediterranean RC building infills (Verderame et al. 2019). Each building type was designed according to three different seismicity sites: (a) L'Aquila (AQ), Naples (NA), and Milan (MI). Soil type "C" (shear wave velocity in the top $30 \mathrm{~m}$ in the range

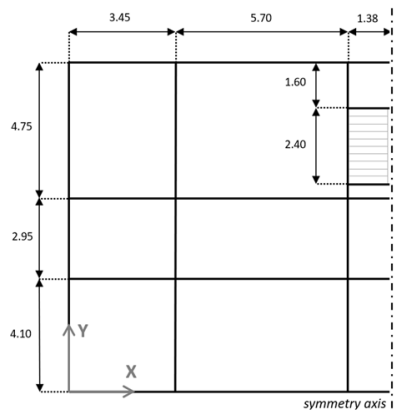

(a)

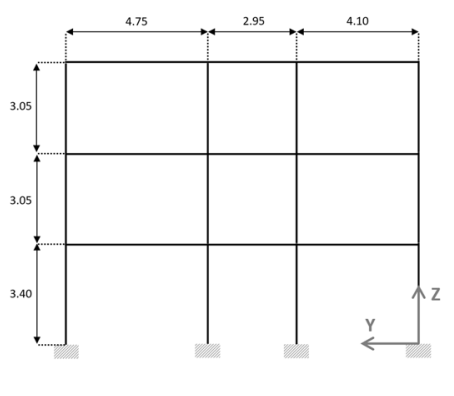

(b)

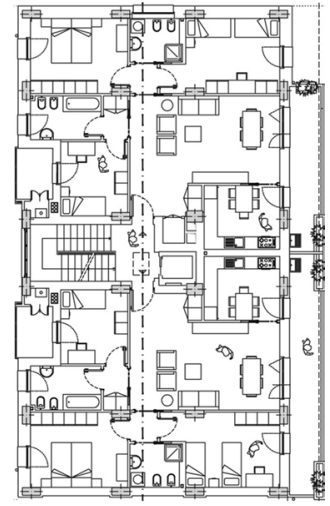

(c)

Fig. 1 a Plan and $\mathbf{b}$ elevation layouts of the frames and $\mathbf{c}$ typical architectural plan. The dimensions are in $\mathrm{m}$ 
Table 2 Site details and design accelerations at bedrock $a_{g}$ related to both SLD and SLV conditions, i.e., 50 and 475 return period $T_{R}$ years (CS.LL.PP. 2018)

Table 3 Summary of the main design parameters

\begin{tabular}{lccll}
\hline Site & Longitude & Latitude & $a_{g}(\mathrm{~g})$ & \\
\cline { 3 - 5 } & & & $\begin{array}{l}\text { SLD } \\
\left(T_{R}=50 \text { years }\right)\end{array}$ & $\begin{array}{l}\text { SLV } \\
\left(T_{R}=475 \text { years }\right)\end{array}$ \\
\hline AQ & 13.399 & 42.349 & 0.104 & 0.261 \\
NA & 14.268 & 40.854 & 0.060 & 0.168 \\
MI & 9.186 & 45.465 & 0.024 & 0.049 \\
\hline
\end{tabular}

\begin{tabular}{llllll}
\hline Site & Building type & $\bar{a}(\%)$ & $\overline{\rho_{b p}}(\%)$ & $\overline{\rho_{b i}}(\mathrm{~s})$ & $\overline{\rho_{c g}^{-}(\%)}$ \\
\hline AQ & BF \& IF & 2.26 & $0.7-1.4$ & $1.0-2.0$ & $1.5-2.1$ \\
& PF & & & & $1.5-2.8$ \\
NA & BF \& IF & \multirow{2}{*}{1.29} & $0.8-1.7$ & $1.0-1.9$ & $1.3-2.1$ \\
& PF & & & & $1.3-2.6$ \\
MI & BF, IF, \& PF & 0.90 & $0.8-1.0$ & $0.6-2.2$ & $1.1-2.3$ \\
\hline
\end{tabular}

180-360 $\mathrm{ms}^{-1}$ ) and topography class 1 (level ground) were considered for all sites. The details of the seismic hazard associated with the investigated sites are reported in Table 2 i.e., maximum bedrock acceleration $\left(a_{g}\right)$ considering both damage limit state (SLD in Italian) and life safety limit state (SLV in Italian). A return period $T_{R}$ equal to 50 (475) years corresponds to the design actions related to SLD (SLV) for ordinary buildings, with 63\% (10\%) probability of exceedance in 50 years. The buildings were designed by performing three-dimensional response spectrum analyses according to the common practice adopted for new buildings. Both SLD and SLV conditions were considered for the design. A ductility class "B" was assumed; this is equivalent to medium ductility class DCM in Eurocode. The behavior factor resulted in 3.9 since the building was regular in both plan and elevation (Fig. 1). Concrete C28/35 and steel B450C (yielding strength equal to $450 \mathrm{Nmm}^{-2}$ ) were used as design materials. Deep perimetrical beams and flat internal beams were assumed as it is common for the considered layout. The floor slabs were one-way $250 \mathrm{~mm}$ thick. The infills/partitions were only considered as applied masses for all buildings according to the current practice, and special design conditions were applied to PF buildings given the irregular infill distribution in elevation. In particular, the seismic actions were amplified by a factor equal to 1.4 for the ground floor columns.

The three-dimensional models had fixed bases and rigid floor diaphragms. The stairwell elements, including the knee beams, were fully considered in the models. A cracked flexural stiffness corresponding to 0.50 and 0.75 times the gross section's one was assumed for beams and columns, respectively. The structural details of all building members are not reported in the paper for the sake of brevity; however, more details on both design process and structural elements can be found in (RINTC Workgroup 2018). The main details of the design are summarized in Table 3 , i.e., the ratio between the ground floor total column area and the total floor area $\bar{a}$, the average of the longitudinal steel ratios related to the perimetrical (internal) beams $\overline{\rho_{b p}}\left(\overline{\rho_{b i}}\right)$, and the average of the longitudinal steel ratios related to the ground floor columns $\overline{\rho_{c g}}$. The cross-section dimensions of all structural members and the reinforcement details of the beams did not vary for BF, IF, and PF buildings for the same sites. 


\section{Numerical analysis}

The numerical models related to the case study buildings were developed in the framework of the Italian RINTC project (RINTC Workgroup 2018; Ricci et al. 2018). Nonlinear static analyses were performed to evaluate the capacity criteria associated with $\mathrm{RDR}_{\mathrm{u} 1}$ and $\mathrm{RDR}_{\mathrm{u} 2}$. Time-history analyses were performed according to a MSA procedure to assess the seismic demand in terms of $\theta$, IDR, and RDR.

\subsection{Numerical modeling}

Three-dimensional models were built in OpenSees (McKenna et al. 2000); they included the frame and stairwell members, as well as the infills when present in the building layout. The structures were fixed at the base (no soil-structure interaction); the floor diaphragms were assumed to be rigid. Since the buildings were designed according to modern capacity design criteria (NTC 2008 (CS.LL.PP. 2008), shear failure of the frame elements and inelastic response of the beam-to-column joints were expected to be prevented (e.g., Ricci et al. 2018). Therefore, the modeling did not account for these latter responses, as well as the end-offsets were not implemented in the models.

\subsubsection{Bare frame and stairwell elements}

A phenomenological model based on lumped plasticity was considered for all frame and stairwell elements. In particular, the inelastic response followed the peak-oriented hysteretic degradation model developed by Ibarra and Krawinkler (2005) and Ibarra et al. (2005), often referred to as IMK model. This model was available within the software database (Karavasilis et al. 2009), and it was widely used in past studies such as in (Haselton et al. 2011; Lin et al. 2013; Ercolino et al. 2018; Ricci et al. 2018; Cimmino et al. 2020; Shahnazaryan and O'Reilly 2021). The IMK model does not account for the influence of the axial force variation on the moment-rotation response, and a fixed value of the axial load has to be assumed for the determination of the modeling parameters. Each structural member was modeled as a series (Fig. 2a), composed of four nodes (two external (frame) nodes and two internal ones) and three elements between them. A zeroLength element was assigned between the frame node and the internal one for each member's end, and an elasticBeamColumn was set between the internal nodes. The uniaxialMaterial ModIMKPeakOriented (IMK model) response was assigned to the zeroLength elements. The P- $\delta$ effects (second order geometrical effects) were also considered in the modeling.

The modeling parameters related to ModIMKPeakOriented response consist of the backbone features and the degrading parameters. The IMK backbone (Fig. 2b) is defined for each (positive/negative) direction by effective yielding moment $M_{y}$, effective elastic stiffness $K_{0}$, strain hardening ratio $\alpha_{s}$ (i.e., hardening to effective elastic stiffness ratio), pre-capping rotation $\Delta \theta_{p}$, and post-capping rotation $\Delta \theta_{p c}$, whereas the degraded capacity parameters consist of the ratio $\kappa$ between the residual moment capacity $M_{r}$ and $M_{y}$ and the ultimate rotation capacity $\theta_{u}$. In Fig. $2 \mathrm{~b}, \theta_{y}, \theta_{c}$, and $\theta_{r}$ are the yielding, capping, and residual rotations, whereas $M_{C}$ and $a_{s}$ are the capping moment and the capping to yielding moment ratio (i.e., $\left.M_{c} / M_{y}\right)$; the strain hardening ratio $\alpha_{s}$ is defined by $\left(M_{c}-M_{y}\right) / \Delta \theta_{p} /$ $K_{0}$ and the hardening stiffness can be expressed by $\alpha_{s} \cdot K_{0}$. 


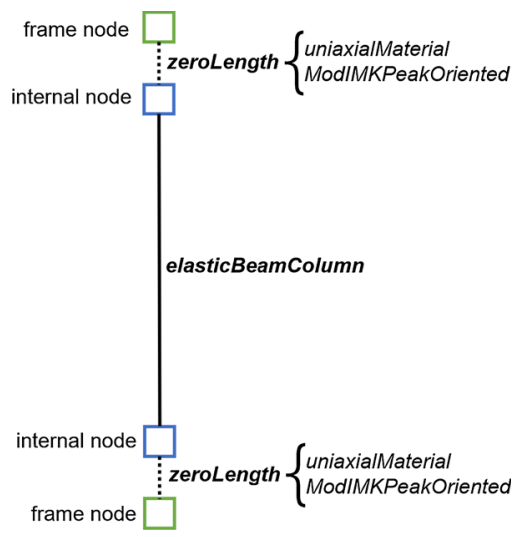

(a)

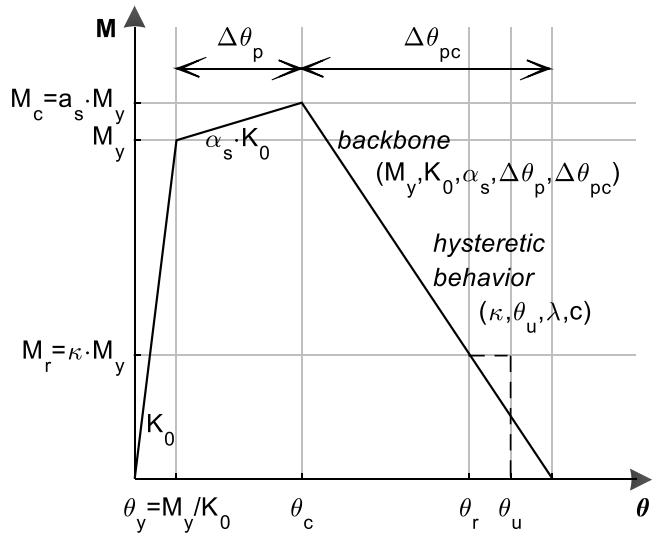

(b)

Fig. 2 Inelastic modeling: a global member model and b IMK backbone curve and hysteretic features of peak-oriented hysteretic response model implemented through uniaxialMaterial ModIMKPeakOriented

For each stage of the response, the hysteretic degradation of both strength and stiffness is taken into account by the parameters $\lambda$ and $c$. An asymmetric hysteretic behavior can also be modeled by setting the rate $D$. For a more detailed description and discussion on the modeling parameters, please see the seminal studies by Ibarra and Krawinkler (2005), Ibarra et al. (2005), Haselton and Deierlein (2007), and Lignos et al. (2011).

The modeling assumes a unique response for the pre-yielding branch (Fig. 2b), and the effective elastic stiffness $K_{0}$ should be ranging between the uncracked and the secantto-yield one; in particular, the implemented stiffness was computed depending on the dimensionless axial force, ranging within $20-60 \%$ of the gross stiffness (RINTC Workgroup 2018). The elastic stiffness of the zeroLength element was assumed to be ten times the elasticBeamColumn one according to several studies (Ibarra and Krawinkler 2005; Ercolino et al. 2018; Iervolino et al. 2018; Magliulo et al. 2018; Ricci et al. 2018), with the series behavior equaling the global member response (Ibarra and Krawinkler 2005). The formulation proposed by Haselton and Deierlein (2007) and Haselton et al. (2008) was considered for the evaluation of the modeling parameters. The formulation details are not reported in the paper since they are well-established in the literature and available in the referenced studies. Moreover, the collapse capacity related to such formulation was already reported in Eqs. 4.1 to 4.4 (Table 1) for the definition of $\theta_{u 4}$.

The capping to yielding moment ratio $a_{s}$ and the residual to yielding moment ratio $\kappa$ were assumed to be equal to 1.13 and zero for all elements according to Haselton and Deierlein (2007). The formulation for $\lambda$ was derived by Lignos et al. (2011), and $c$ was assumed to be equaling zero. A symmetric hysteretic response was considered by assuming $D$ equal to one.

The stairwell elements consisted of full-height and inter-floor short columns, inclined beams, and floor and inter-floor beams. Such elements were modeled analogously to the frame elements, even though some modifications were made for the inclined beams because of their peculiar geometry. In particular, the stiffness of the axial degree of freedom of the elasticBeamColumn elements (related to the inclined beams) was assumed equal to zero, and an inelastic truss element was added in parallel. An asymmetric elastic-plastic behavior was assigned to the truss element. 
Mass- and initial tangent stiffness-proportional Rayleigh damping was assumed, with a damping ratio equal to $5 \%$ assigned to (a) half of the first mode frequency (due to the period elongation phenomena) and (b) second mode frequency of the prevalently translational modes. According to Ibarra and Krawinkler (2005), the damping was only assigned to the elasticBeamColumn elements (Fig. 2a). This allowed avoiding the typical issues related to the damping forces generated by the sudden stiffness variation within the plastic hinges over the plastic range behavior (Charney 2008; Ricci et al. 2018).

\subsubsection{Infill panels}

The presence of the infills was taken into account within the global building model by implementing their in-plane response. Each infill panel (Fig. 3a) was modeled by two symmetric independent diagonal strut elements only responding under compression (Fig. 3b).

The modeling was implemented according to Decanini and Fantin (1986), Bertoldi et al. (1993), Decanini et al. (2004, 2014). The equivalent strut behavior of the infills depends on the characteristics of the panel (e.g., Fig. 3a). The width of the equivalent strut element $\bar{\omega}$ (Fig. 3b) was computed according to Smith (1962), i.e. by using Eq. (12), where $K_{1}$ and $K_{2}$ are experimental constants defined in Eq. (13), $\lambda h$ is a dimensionless relative stiffness parameter defined in Eq. (14), and $d_{p}$ is the equivalent strut length. In Eq. (14), $E_{m}$ is the equivalent elastic modulus of the infills, $e$ is the thickness of the panel, $\phi$ is the strut-to-frame beam angle, $E_{c}$ is the elastic modulus of the concrete, $I$ is the moment of inertia of the columns, $h$ is the (centerline) height of the story, and $h_{p}$ is the infill panel height.

$$
\bar{\omega}=\left(\frac{\mathrm{K}_{1}}{\lambda \mathrm{h}}+\mathrm{K}_{2}\right) d_{p}
$$

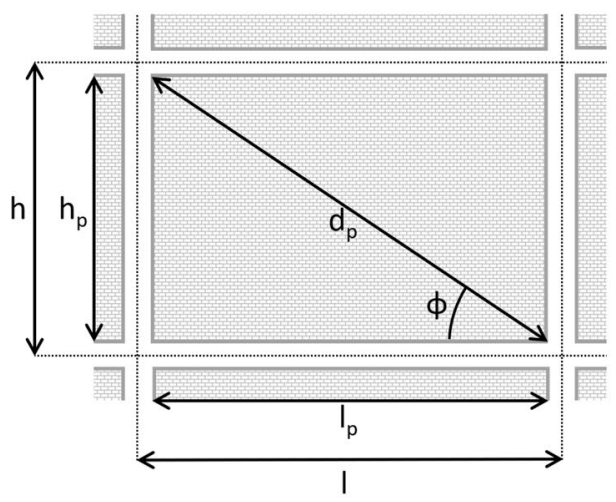

(a)

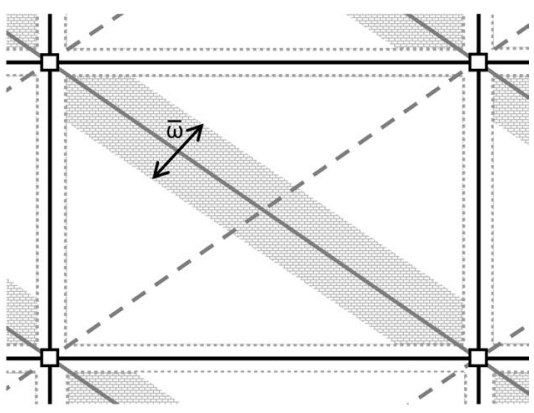

(b)

Fig. 3 a Geometry of an infill panel and b schematic of the frame and strut elements. The dotted black (solid grey) lines in a are representative of the axis (external edges) of the frame structure, whereas the brick pattern fields depict the infill panels. The square elements in $\mathbf{b}$ represent the frame nodes; the solid black lines are representative of the modeling frame elements, whereas the solid and dashed grey lines depict the modeling strut elements 


$$
\begin{gathered}
\mathrm{K}_{1}\left(\mathrm{~K}_{2}\right)= \begin{cases}1.3(-1.78) & \text { if } \lambda \mathrm{h} \leq 3.14 \\
0.707(0.01) & \text { if } 3.14 \leq \lambda \mathrm{h} \leq 7.85 \\
0.47(0.04) & \text { if } \lambda \mathrm{h} \geq 7.85\end{cases} \\
\lambda \mathrm{h}=\sqrt[4]{\frac{\mathrm{E}_{\mathrm{m}} \mathrm{e} \sin 2 \phi}{4 \mathrm{E}_{\mathrm{c}} \mathrm{Ih}_{\mathrm{p}}}} \mathrm{h}
\end{gathered}
$$

The strut behavior is modeled by a backbone curve, defined as lateral force $H_{m}$ versus displacement $u$ (Fig. 4), and consisting in four branches: (a) elastic pre-cracking, (b) post-cracking, (c) softening, and (d) plastic (or residual). The elastic branch is defined by the cracking lateral force and displacement $H_{m f}$ and $u_{f}$ (F in Fig. 4), whereas the peak strength condition is defined by the peak lateral force and the corresponding displacement $H_{m f c}$ and $u_{f c}$ (FC in Fig. 4). The residual conditions are defined by the residual lateral force and displacement $H_{m r}$ and $u_{r}$.

$H_{m f_{c}}$ was found using Eq. 15, where $\gamma_{m}$ is a factor used to obtain a median value from the experimental (lognormal) estimation, and $\sigma_{\min }$ is defined in Eq. 16. In particular, $\sigma_{\text {min }}$ is the minimum value among the considered failure mode compression strengths, i.e., (a) diagonal tension $\left(\sigma_{b r 1}\right)$, (b) sliding shear along the horizontal joints $\left(\sigma_{b r 2}\right)$, (c) crushing in the corner in contact with the frame $\left(\sigma_{b r 3}\right)$, and (d) diagonal compression $\left(\sigma_{b r 4}\right)$. Such failure modes describe the typical seismic response of infill panels evidenced by experimental tests and post-event surveys. The failure mode strengths $\sigma_{b r l}$ to $\sigma_{b r 4}$ are defined in Eqs. (17-20) where $\sigma_{0}$ is the vertical stress due to the gravitational loads, $\tau_{m 0}$ is shear strength measured through diagonal compression tests, $f_{s r}$ is the sliding strength in the joints, and $\sigma_{m 0}$ is the vertical compression strength measured on masonry specimens.

$$
\begin{gathered}
\mathrm{H}_{\mathrm{mfc}}=\gamma_{\mathrm{m}} \sigma_{\min } e \bar{\omega} \cos \phi \\
\sigma_{\min }=\min \left\{\sigma_{\mathrm{br} 1}, \sigma_{\mathrm{br} 2}, \sigma_{\mathrm{br} 3}, \sigma_{\mathrm{br} 4}\right\}
\end{gathered}
$$

Fig. 4 Backbone curve related to the equivalent strut element (Decanini and Fantin 1986; Bertoldi et al. 1993; Decanini et al. 2004, 2014)

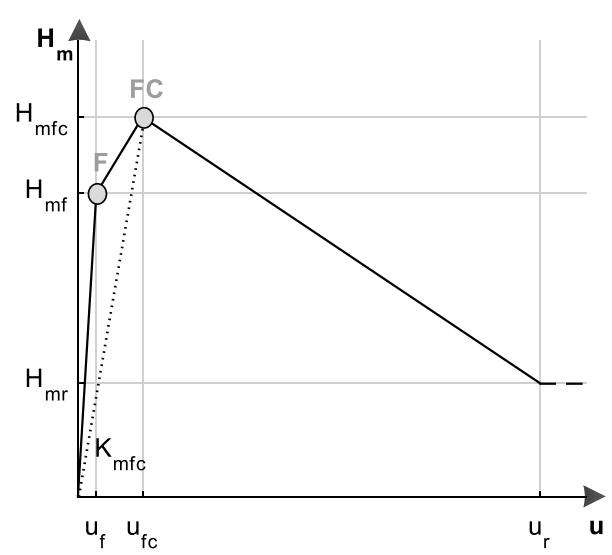




$$
\begin{gathered}
\sigma_{\mathrm{br} 1}=\frac{0.3 \sigma_{0}+0.6 \tau_{\mathrm{m} 0}}{\frac{\bar{\omega}}{\mathrm{d}_{\mathrm{p}}}} \\
\sigma_{\mathrm{br} 2}=\frac{0.3 \sigma_{0}+\mathrm{f}_{\mathrm{sr}}(1.2 \sin \phi+0.45 \cos \phi)}{\frac{\bar{\omega}}{\mathrm{d}_{\mathrm{p}}}} \\
\sigma_{\mathrm{br} 3}=\sigma_{\mathrm{m} 0} \frac{1.12 \sin \phi \cos \phi}{\mathrm{K}_{1}(\lambda h)^{-0.12}+\mathrm{K}_{2}(\lambda h)^{-0.88}} \\
\sigma_{\mathrm{br} 4}=\sigma_{\mathrm{m} 0} \frac{1.16 \sigma_{\mathrm{m} 0} \tan \phi}{\mathrm{K}_{1}+\mathrm{K}_{2} \lambda h}
\end{gathered}
$$

$H_{m f}$ and $H_{m r}$ were assumed to be 0.8 and 0.35 times $H_{m f c}$, respectively, whereas the displacement limits related to the backbone curve (i.e., $u_{f}, u_{f c}, u_{r}$ ) were derived from recent studies (Cardone and Perrone 2015; Sassun et al. 2016). The factor $\gamma_{m}$ was assumed equal to 1.18. The elastic modulus of the infill panel $E_{m}$ resulted in $4.312 \mathrm{GPa}$. The vertical stress $\sigma_{0}$ was equal to zero, and the compression strength $\sigma_{m 0}$ was set equal to $6 \mathrm{MPa}$. The shear strength $\tau_{m 0}$ was assumed to be equal to $\sqrt{\sigma_{m 0}}$ (where $\sigma_{m 0}$ is in $\mathrm{Kg} / \mathrm{cm}^{2}$ ), resulting in 0.77 $\mathrm{MPa}$, whereas the sliding strength $f_{s r}$ was set equal to $0.7 \tau_{m 0}$, resulting in $0.54 \mathrm{MPa}$. Such assumptions were corroborated by other past studies (Camata et al. 2017; Terrenzi et al. 2018; Ricci et al. 2018), and widely discussed in (RINTC Workgroup 2018).

The presence of the openings within the infill panels was also taken into account by assuming a reduction in both stiffness and strength of the strut behavior, according to Decanini et al. (2014). The reduction coefficient $\rho_{o}$ defined in Eq. (21) was applied to both the (full panel) ultimate strength $H_{m f c}$ and secant stiffness $K_{m f_{c}}$. In particular, $\alpha_{a}$ and $\alpha_{1}$ are defined in Eqs. (22) and (23), respectively, where $l_{0}$ and $h_{0}$ are the horizontal and vertical dimensions of the opening. The presence of the opening was implemented in the global models according to the architectural layout shown in Fig. 1c.

$$
\begin{gathered}
\rho_{\mathrm{o}}=0.55 \exp \left(-0.035 \alpha_{\mathrm{a}}\right)+0.44 \exp \left(-0.025 \alpha_{1}\right) \\
\alpha_{\mathrm{a}}=100 \frac{\mathrm{l}_{0} \mathrm{~h}_{0}}{1_{\mathrm{p}} \mathrm{h}_{\mathrm{p}}} \\
\alpha_{1}=100 \frac{1_{0}}{\mathrm{l}_{\mathrm{p}}}
\end{gathered}
$$

The infill panel strut response was implemented by assigning the uniaxial Material Concrete01 behavior to the diagonal elements (Fig. 3b). In fact, this response was able to fit the backbone curve with good agreement, with particular regard to the initial elastic and the softening branches (RINTC Workgroup 2018). 


\subsection{Static and time history analyses}

Nonlinear static analyses were performed considering both uniform (UNI) and modal (MOD) force distributions in both positive/negative horizontal directions $\left(\mathrm{X}, \mathrm{Y}^{-}\right.$, and $\left.\mathrm{Y}^{+}\right)$. PO curves were produced in terms of $V_{h}$ versus RDR. Bidirectional nonlinear MSA (Jalayer 2003; Scozzese et al. 2020) was performed by considering the conditional spectrum (CS) approach for the definition of the loading histories (Jayaram et al. 2011; Lin et al. 2013). In particular, the analysis records were derived by Iervolino et al. $(2017,2018)$. The spectral acceleration corresponding to the fundamental period of the buildings $\operatorname{Sa}\left(T_{1}\right)$ was assumed as IM. Ten IM levels (or stripes) were defined by assuming the return period $T_{R}$ equal to $10,50,100,250,500,1000,2500,10,000$, and 100,000 years. For each IM level, 20 pairs of records (i.e., both horizontal components) were selected from the Italian accelerometric archive ITACA (http://itaca.mi.ingv.it) and the NGAwest2 database (http://peer.berkeley. edu/ngawest2/), and they were processed in order to achieve the compatibility with the conditional spectral accelerations. The fundamental periods $T_{1}$ used for the spectral processing were assumed equal to $1.00,0.50$, and $0.15 \mathrm{~s}$ for $\mathrm{BF}, \mathrm{PF}$, and IF respectively, according to the modal response of the building typologies (RINTC Workgroup 2018; Suzuki and Iervolino 2019). As a representative depiction, the acceleration spectra $S a(T)$ related to AQ site (soil type C) are reported in Fig. 5, considering (a) the maximum component spectra and median/percentiles related to IM level 7 and (b) the median spectra related to all IM levels. The spectral acceleration related to the fundamental building period $S a\left(T_{1}\right)$ is plotted versus $T_{R}$ (and related IM levels) in Fig. 6 for all sites and building typologies.

\section{Collapse characterization}

\subsection{Methodology}

The collapse capacity and seismic demand related to the investigated buildings were assessed to characterize the different capacity criteria as a function of the building behavior and collapse features. The characterization of the collapse capacity criteria was expressed

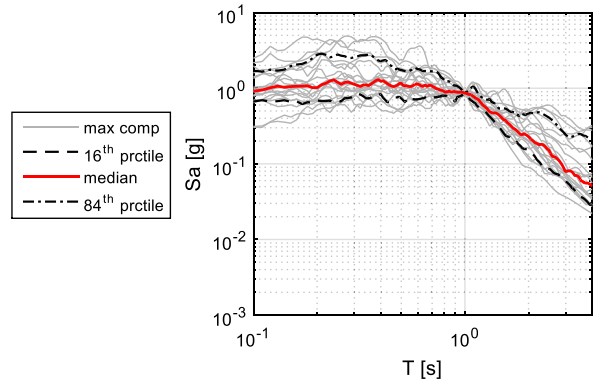

(a)

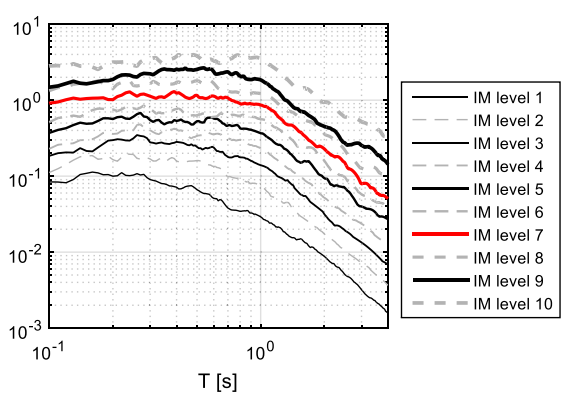

(b)

Fig. 5 Acceleration spectra $\mathrm{Sa}(\mathrm{T})$ related to $\mathrm{AQ}$ site, considering a maximum component spectra (max comp), median, and 16th/84th percentiles related to IM level 7, and b median spectra related to all IM levels 


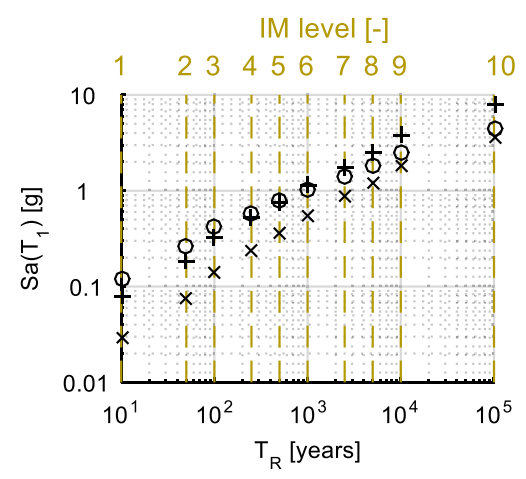

(a)

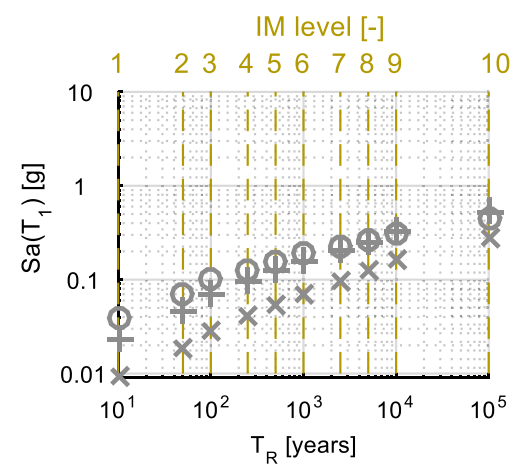

(c)

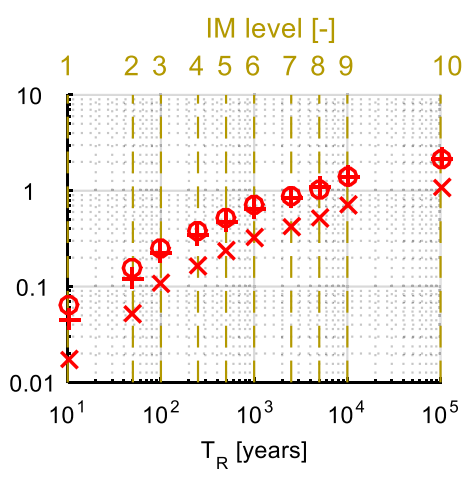

(b)

\begin{tabular}{|cl|}
\hline$\times$ & AQ BF \\
+ & AQ IF \\
0 & AQ PF \\
$\times$ & NABF \\
+ & NAIF \\
0 & NAPF \\
$\times$ & MI BF \\
+ & MI IF \\
0 & MIPF \\
\hline
\end{tabular}

Fig. 6 Spectral acceleration corresponding to the fundamental vibration period $S a\left(T_{1}\right)$ versus return period $T_{R}$ and corresponding IM level, related to a AQ, b NA, and $\mathbf{c}$ MI sites

in terms of EDP capacities, demand to capacity ratios, fragility curves (building capacity estimation), estimated and target collapse margin ratios and probabilities (building collapse performance), and inter-capacity margin ratios.

The EDP collapse capacities were evaluated in the study, and they presented in Sect. 5.2; these were computed as described in Sect. 2. The chord rotation and inter-story drift ratio capacities $\left(\theta_{u}\right.$ and IDR ${ }_{u}$, respectivelty) were estimated considering formulations and criteria derived from regulations and literature (Table 1), whereas the roof drift ratio capacities $\left(\mathrm{RDR}_{\mathrm{u}}\right)$ were estimated by processing the PO curves related to the performed numerical analyses (Sect. 4), according to literature studies.

The demand to capacity ratio $(D / C)$ can be considered as a damage ratio of the structural members (e.g., Panagiotakos and Fardis 2004). D/C was evaluated as a function of (a) capacity criterion and (b) IM level. The $D / C$ ratios were evaluated in the study and reported in Sect. 5.3. Considering the $i$ th capacity criterion and the $j$ th IM level, the $k$ th data point represents the maximum ratio between the (maximum) seismic demand and the $i$ th capacity criterion, where the seismic demand is related to the $j$ th IM level and $k$ th loading history, and both demand and capacity are expressed in terms of the $i$ th capacity criterion EDP. The (maximum) $D / C$ ratios related to the ultimate chord rotation $\theta_{u}$ (inter-story drift ratio $\left(\mathrm{IDR}_{\mathrm{u}}\right.$ ) were defined as the maximum values among the ratios evaluated for frame 
and stairwell elements (all stories) related to both directions. The maximum $D / C$ ratios related to the ultimate roof drift ratio $\left(\mathrm{RDR}_{\mathrm{u}}\right)$ were defined as the maximum values among the ratios related to both directions.

The fragility was defined as the probability that EDP exceeds or equals the EDP (capacity) threshold edp, given IM equal to $S a\left(T_{1}\right)$, i.e., $P\left[E D P \geq e d p \mid S a\left(T_{1}\right)\right]$. The fragility was computed according to type- $B$ or bounding method, defined by Porter et al. (2006, 2007), and a lognormal best-fitting model was assumed to fit the recordto-record data variability. The other sources of uncertainty (e.g., design requirements and modeling uncertainties) were not explicitly taken into account for the computation of the fragility curves since (a) the focus of the fragility assessment was on the recordto-record variability and (b) the other sources were not accurately estimated in the present study. The fragility median and (record to record) logarithmic standard deviation parameters are defined as $m$ and $\beta$. Porter method was widely used in the literature (e.g., Di Sarno et al. 2019; Cremen and Baker 2019); therefore, the formulation is omitted for the sake of brevity. The fragility assessment was performed in the study and is reported in Sect. 5.4, considering the results related to AQ site buildings since the NA and MI buildings did not present an adequate minimum number of collapses corresponding to the highest IM level for all capacity criteria (e.g., Baker 2015; Suzuki and Iervolino 2019).

The collapse margin ratio represents a measure of the safety level of the building concerning the collapse and the collapse safety reserve (Haselton et al. 2011; Rofooei and Seyedkazemi 2020). The collapse margin ratio can be defined as the ratio between the median collapse capacity and the spectral demand of the maximum considered earthquake (MCE) ground motion (Federal Emergency Management Agency (FEMA) 2009; NEHRP Consultants Joint Venture 2010; American Society of Civil Engineers 2017b). The collapse performance was evaluated in this study, and the results are reported in Sect. 5.5. In particular, the estimated collapse margin ratios were computed and compared to the related acceptable or target values. The collapse margin ratios $Z_{2 / 50}$ and $Z_{5 / 50}$ were computed as shown in Eqs. (24) and (25), i.e., by considering the previously defined $S a\left(T_{1}\right)_{2 / 50}$ and $S a\left(T_{1}\right)_{5 / 50}$ as a spectral demand related to the MCE ground motion, respectively. It is worth mentioning that the reference collapse margin ratio assessment and the related performance evaluation were developed considering risktargeted ground motion maps in the US and referring to the (risk-targeted) MCE ground motions (Federal Emergency Management Agency (FEMA) 2009; American Society of Civil Engineers 2017b). Some insightful technical comments regarding (risk-targeted) MCE ground motions and collapse assessment can be found in the seminal studies by Haselton et al. (2017) and Fajfar (2018). It is recalled that (a) $S a\left(T_{1}\right)_{2 / 50}$ and $S a\left(T_{1}\right)_{5 / 50}$ represent the $S a\left(T_{1}\right)$ values conditional to $2 \%$ and $5 \%$ probability of exceedance in 50 years for the considered site and soil condition (corresponding to return period $T_{R}$ equal to 2475 and 975 years, respectively) and (b) $m$ is the median value of the collapse fragility (expressed as $\mathrm{Sa}\left(\mathrm{T}_{1}\right)$ ), considering a given collapse criterion. The conditional collapse probability (Sect. 5.5) can be defined as the fragility curve ordinate associated with the spectral demand related to the MCE ground motion, which in this case corresponds to $S a\left(T_{1}\right)_{2 / 50}$ and $S a\left(T_{1}\right)_{5 / 50}$.

$$
\mathrm{Z}_{2 / 50}=\frac{\mathrm{m}}{\mathrm{Sa}\left(\mathrm{T}_{1}\right)_{2 / 50}}
$$




$$
\mathrm{Z}_{5 / 50}=\frac{\mathrm{m}}{\mathrm{Sa}\left(\mathrm{T}_{1}\right)_{5 / 50}}
$$

A value equal to $10 \%$ was assumed as a target collapse probability $\left(\bar{P}_{c}\right)$, according to (Federal Emergency Management Agency (FEMA) 2009; American Society of Civil Engineers 2017b). The acceptable collapse margin ratio $(\bar{Z})$ was defined as it was recommended in (Federal Emergency Management Agency (FEMA) 2009; Zhang and He 2020), i.e., according to Eq. (26), where $\beta_{T O T}$ is the total uncertainty (i.e., logarithmic standard deviation including all main uncertainty sources), and $\Phi_{S T D}$ represents the cumulative distribution function (CDF) of the standard normal distribution.

$$
\overline{\mathrm{Z}}=\exp \left(-\beta_{\mathrm{TOT}} \Phi_{\mathrm{STD}}^{-1}\left(\overline{\mathrm{P}}_{\mathrm{c}}\right)\right)
$$

The collapse margin ratios (e.g., $Z_{2 / 50}$ and $Z_{5 / 50}$ ) are not directly affected by the dispersion of the fragility curves, but the dispersion affects the value of the acceptable collapse margin $\bar{Z}$ (Eq. 26). In particular, $\bar{Z}$ increases exponentially with $\beta_{T O T}$ (e.g., Eq. 26 (Zhang and He 2020)). The conditional collapse probability is directly conditioned by the fragility dispersion and tends to increase as the standard deviation increases (e.g., (Federal Emergency Management Agency (FEMA) 2009)). Some further insights and recent development regarding target collapse margin ratios and collapse probabilities can be found in (Douglas and Gkimprixis 2018; Zhang and He 2020).

For the abovementioned reasons, $\bar{Z}$ was evaluated considering both record-to-record uncertainty $(\beta)$ and total uncertainty $\left(\beta_{T O T}\right)$. This latter was defined according to (Federal Emergency Management Agency (FEMA) 2009) and is reported in Eq. (27), where design requirements uncertainty $\left(\beta_{D R}\right)$, test data uncertainty $\left(\beta_{T D}\right)$, and modeling uncertainty $\left(\beta_{M D L}\right)$ were assumed to be equal to 0.30 , i.e., an average value evaluated over the recommended range of values, which is also compliant with typical values suggested in other literature studies (e.g., Porter et al. 2006).

$$
\beta_{\mathrm{TOT}}=\sqrt{\beta^{2}+\beta_{\mathrm{DR}}^{2}+\beta_{\mathrm{TD}}^{2}+\beta_{\mathrm{MDL}}^{2}}
$$

The inter-capacity margin ratio $Z_{X}^{Y}$ is defined in Eq. (28), where $X$ and $Y$ are the two capacity criteria between which the margin has to be assessed and $m_{X}$ and $m_{Y}$ are the related median values. The inter-capacity margin ratios were computed in the study, and the most relevant results are reported in Sect. 5.6.

$$
\mathrm{Z}_{\mathrm{X}}^{\mathrm{Y}}=\frac{\mathrm{m}_{\mathrm{Y}}}{\mathrm{m}_{\mathrm{X}}}
$$

Assessing the inter-capacity margin ratios identified between different criteria allows (a) checking the effects of the design process and prescriptions and (b) assessing the local to global collapse response and the yielding to heavily plastic behavior of the building. These margin ratios correlate in a quantitative manner the different criteria and relate their characteristics to the resulting building capacity. As an example, regular code-conforming buildings are expected to exhibit a relatively simultaneous degradation process of the ductile element sections, having the distribution of the plastic behavior as spread as possible over the candidate elements and regions. Then, while the margin, in terms of displacements, between the development of a global plastic behavior and the earliest element section collapse should be significant, the capacity margin between the earliest (ductile) element section collapse and the global collapse should be as reduced as possible, showing consistency between the global response 
and the behavior of the single members. Such (inter-capacity) margin can be considered as an irregularity feature of the building behavior.

\subsection{EDP capacities}

The empirical chord rotation formulations $\left(\theta_{u 1}\right.$ and $\left.\theta_{u 3}\right)$ produce quite similar capacities for all elements, and the new Eurocode draft capacity $\left(\theta_{u 3}\right)$ is typically slightly smaller than the current one. The physical formulation $\left(\theta_{u 2}\right)$ often determines capacities larger than the empirical ones $\left(\theta_{u 1}\right.$ and $\left.\theta_{u 3}\right)$; this is more significant for element sections that present a significant ultimate curvature. A similar trend was already found by Fusco et al. (2018), who compared the current Eurocode empirical and the physical (or mechanical-empirical) formulations to the experimental results related to literature tests on rectangular columns (it is worth specifying that the experimental database considered in (Fusco et al. 2018) was related to a wide range of geometrical and mechanical properties, which are in average not very similar to the ones related to the present study). The variation of the ultimate curvature directly affects the physical rotational capacity (Eq. 2.1), while this influence is less direct for the empirical ones. The difference between the HD capacity $\left(\theta_{u 4}\right)$ and the empirical ones was quite irregular, and the former (latter) was often larger than the latter (former) for columns (beams). The considered $\mathrm{IDR}_{\mathrm{u}}$ capacities were already defined in Table 1 . The roof drift $(\mathrm{RD})$ values associated with the $\mathrm{RDR}_{\mathrm{u}}$ capacities $\left(\mathrm{RD}_{\mathrm{u} 1}\right.$ and $\left.\mathrm{RD} \mathrm{u} 2\right)$ are reported in Table 4 for both $\mathrm{X}$ and $\mathrm{Y}$ directions. The assumed $\mathrm{RDR}_{\mathrm{u}}$ capacities (i.e., minimum values over the different cases) are reported in Fig. 7 as RD values for (a) $\mathrm{X}$ and (b) $\mathrm{Y}$ directions. The PO curves are available in (RINTC Workgroup 2018; Ricci et al. 2018).

\subsection{Demand to capacity ratios}

Figures 8,9 , and 10 depict the demand $(D)$ to capacity $(C)$ ratios $(D / C)$ considering all capacity criteria and all building typologies for AQ, NA, and MI, respectively. The different building typology clearly affects the trend of $\mathrm{D} / \mathrm{C}$ over the investigated collapse criteria. For instance, $\mathrm{RDR}_{\mathrm{u}}$ capacities (overall) resulted in the least conservative ratios for (all sites) $\mathrm{BF}$ and $\mathrm{PF}$, whereas for IF (all sites) they produced ratios more similar to the other types of capacity. The discrepancy between $\mathrm{RDR}_{\mathrm{u} 1}$ and $\mathrm{RDR}_{\mathrm{u} 2}$ was quite reduced (significant) for $\mathrm{BF}$ and $\mathrm{PF}$ (IF). IDR $\mathrm{I}_{\mathrm{1}}$ was particularly severe compared to the other $\mathrm{IDR}_{\mathrm{u}}$ capacities, which produced quite similar $\mathrm{D} / \mathrm{C}$ ratios; this was more significant for $\mathrm{IF}$ and $\mathrm{PF}$ as the $\mathrm{IDR}_{\mathrm{u} 1}$ threshold was reduced for infilled inter-stories. IDR $\mathrm{u}_{\mathrm{5}}$ was associated with the lowest $\mathrm{D} / \mathrm{C}$ ratios, which were followed by $\mathrm{RDR}_{\mathrm{u} 2}$ one in terms of magnitude. It is recalled that $\mathrm{IDR}_{\mathrm{u} 5}$ could be representative of a condition relatively close or coinciding with sidesway collapse, as it was discussed in Sect. 2.1.

The similarity between $\theta_{u 1}$ and $\theta_{u 3}$ produced very similar D/C results, and $\theta_{u 1}$ was the least conservative capacity; $\theta_{u 2}$ produced $\mathrm{D} / \mathrm{C}$ ratios intermediate between the empirical and the HD capacity ones. No collapse occurred corresponding to the SLV state (i.e., IM level 5) for (all sites) BF, with (all capacity) D/C ratios ranging in 0.1 to 0.6 for AQ. IF and $\mathrm{PF}$ buildings were more critical (considering $\mathrm{IDR}_{\mathrm{u} 1}$ ) since one collapse occurred at SLV for AQ IF, almost one (maximum D/C equal to about 0.95) for AQ PF, and almost one for NA IF (maximum D/C equal to about 0.98). It is worth noting that the collapses related to IM level 8 BF MI (one case out of 20 for all capacities) were related to dynamic instability, 


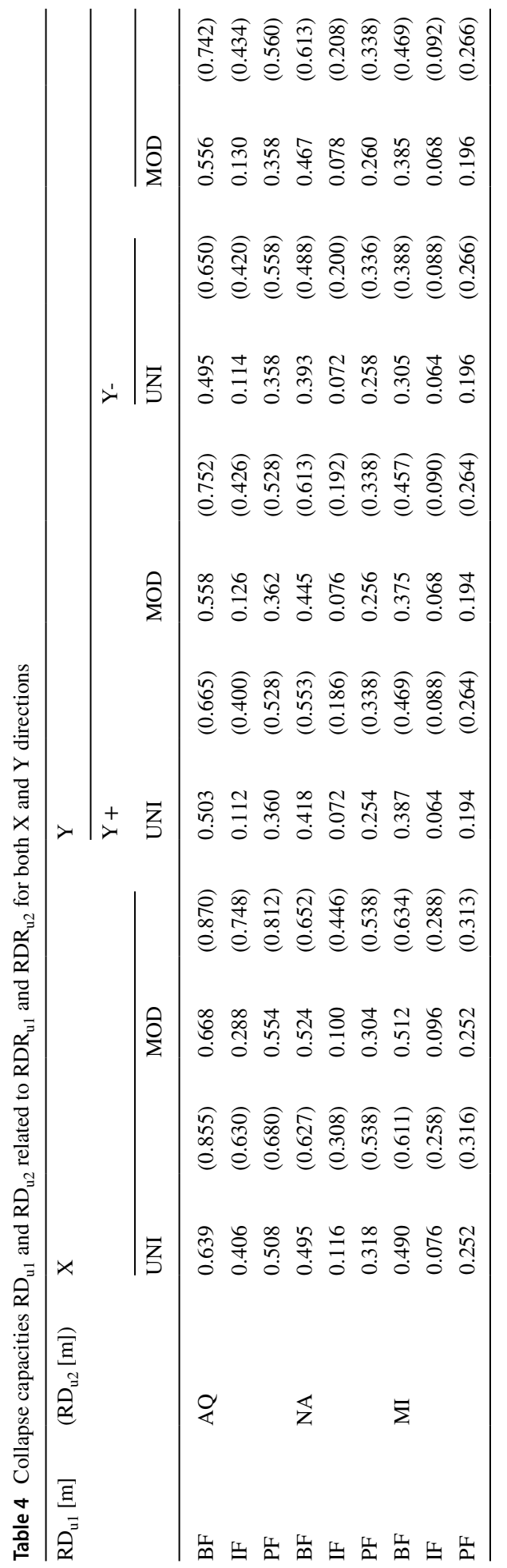




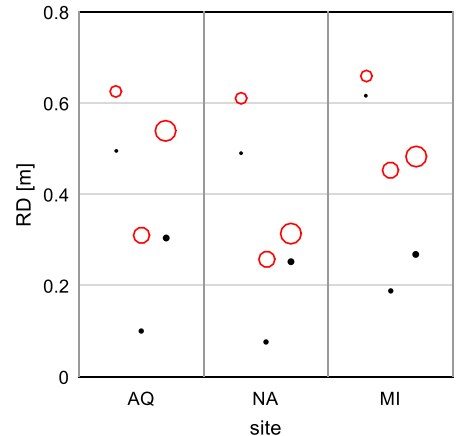

(a)

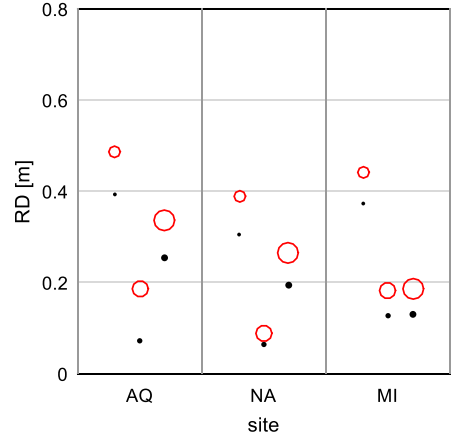

(b)

Fig. 7 Minimum collapse capacities related to $\mathrm{RDR}_{\mathrm{u} 1}$ and $\mathrm{RDR}_{\mathrm{u} 2}$ plotted as $\mathrm{RD}$ values for $\mathbf{a} \mathrm{X}$ and $\mathbf{b} \mathrm{Y}$ directions

and they were probably caused by numerical issues; however, they were not neglected for the sake of completeness.

The collapse occurrences $N_{C O}, N_{C l}$, and $N_{C T}$ related to the chord rotation capacities $\theta_{u}$ are reported in Table 5 for each element type of all AQ site buildings and corresponding to IM levels 9 and 10; four element types are taken into account, i.e., frame column, frame beam, stairwell short column, and stairwell short beam. In particular, for a given IM level, $N_{C O}$ is the number of occurrences out of 20 pairs of records in which at least a member section of the specific element type reached collapse, whereas $N_{C l}$ is the number of occurrences in which at least a member section of the specific element type reached collapse while no member section of any other element type collapsed. $N_{C T}$ is the total number of collapse occurrences out of 20 pairs of records considering all element types together. Obviously, the difference between $N_{C l}$ and $N_{C O}$ represents the occurrences in which the collapse of at least an element section of the specific element type occurs together with the collapse of at least an element section of any other element type (e.g., one beam section and one column section collapsed). The frame elements typically exhibit less collapses if compared to the stairwell elements, as it can be seen by comparing the related $N_{C O}$ values. $N_{C 1}$ is equal zero for columns in all cases, whereas it equals one for beams in very few cases (reported in bold). The stairwell elements are quite more critical than the frame members $\left(N_{C 0}\right)$, and they collapse earlier than these latter in some cases (e.g., $N_{C l}$ is nonzero in some cases). No significant differences were identified comparing stairwell short columns and beams in terms of collapse occurrences $\left(N_{C 0}\right.$ and $\left.N_{C 1}\right)$. In most cases, when an element type section collapsed, at least a section of any other element types reached collapse as well, showing that the collapse involves more element types. Some insights into the correlation between the collapse capacity criteria and the inelastic behavior of the buildings are also reported in the following sections.

\subsection{Fragility curves}

Figure 11 shows the fragility curves related to (a) BF, (b) IF, and (c) PF buildings; Table 6 reports the related values of the median $(m)$ and logarithmic standard deviation $(\beta)$ for comparison purposes. The $S a\left(T_{1}\right)$ values conditional to $2 \%$ and $5 \%$ probability of exceedance 


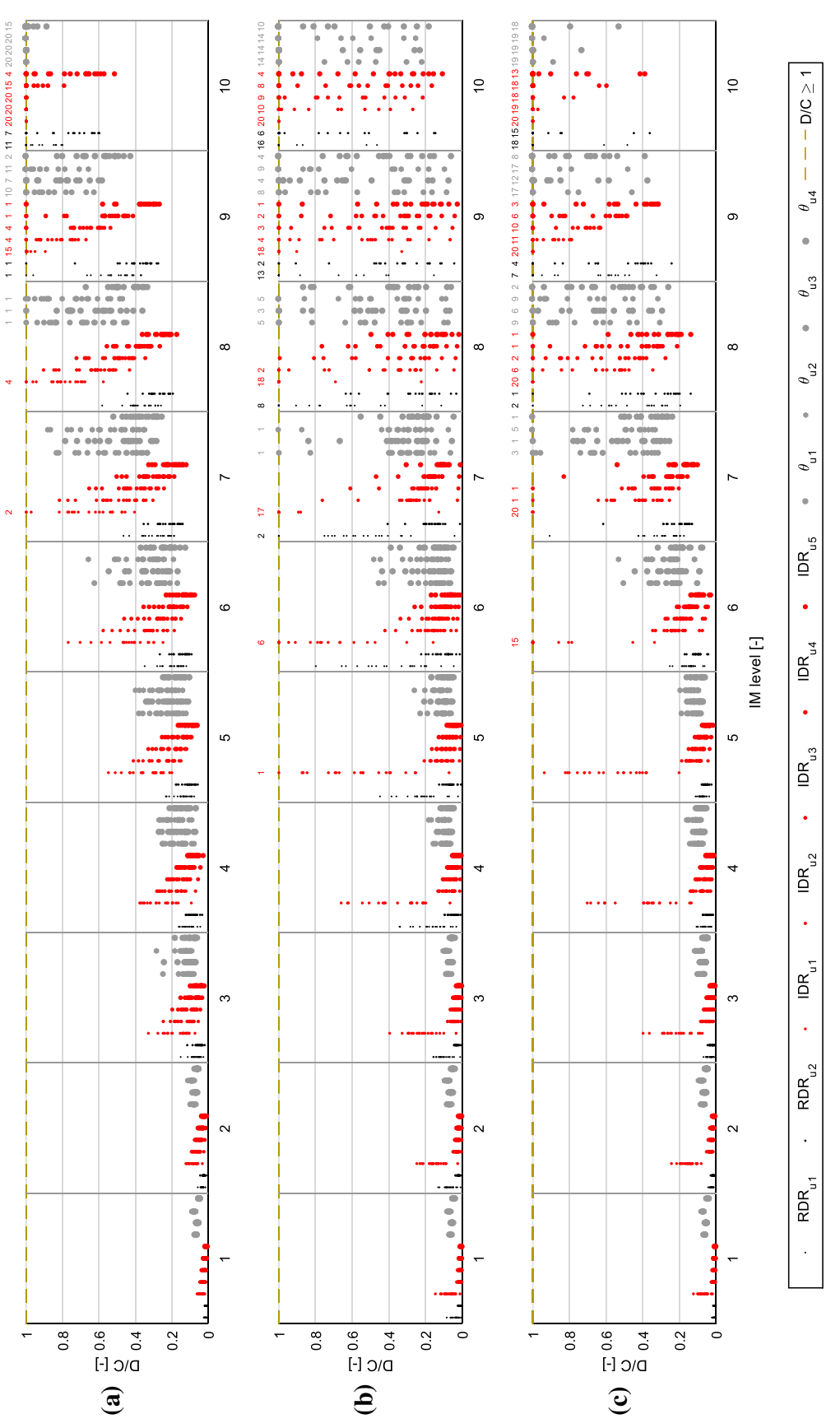

콣 융

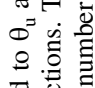

럴

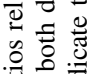

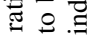

总 훔

它

寻市完

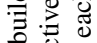

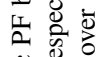

它楁

生产

둥

咹

๘

용

를

安言

월

政

要

需 9

氜 矛

ج记

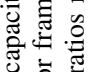

过

产过

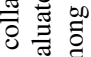

สี วิ

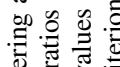

可 覀.

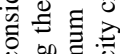

仓

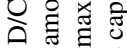

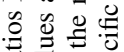

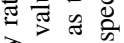

쿠웡

手. 表

옐

월

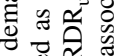

छ

寻它

宏离豞

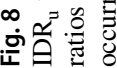




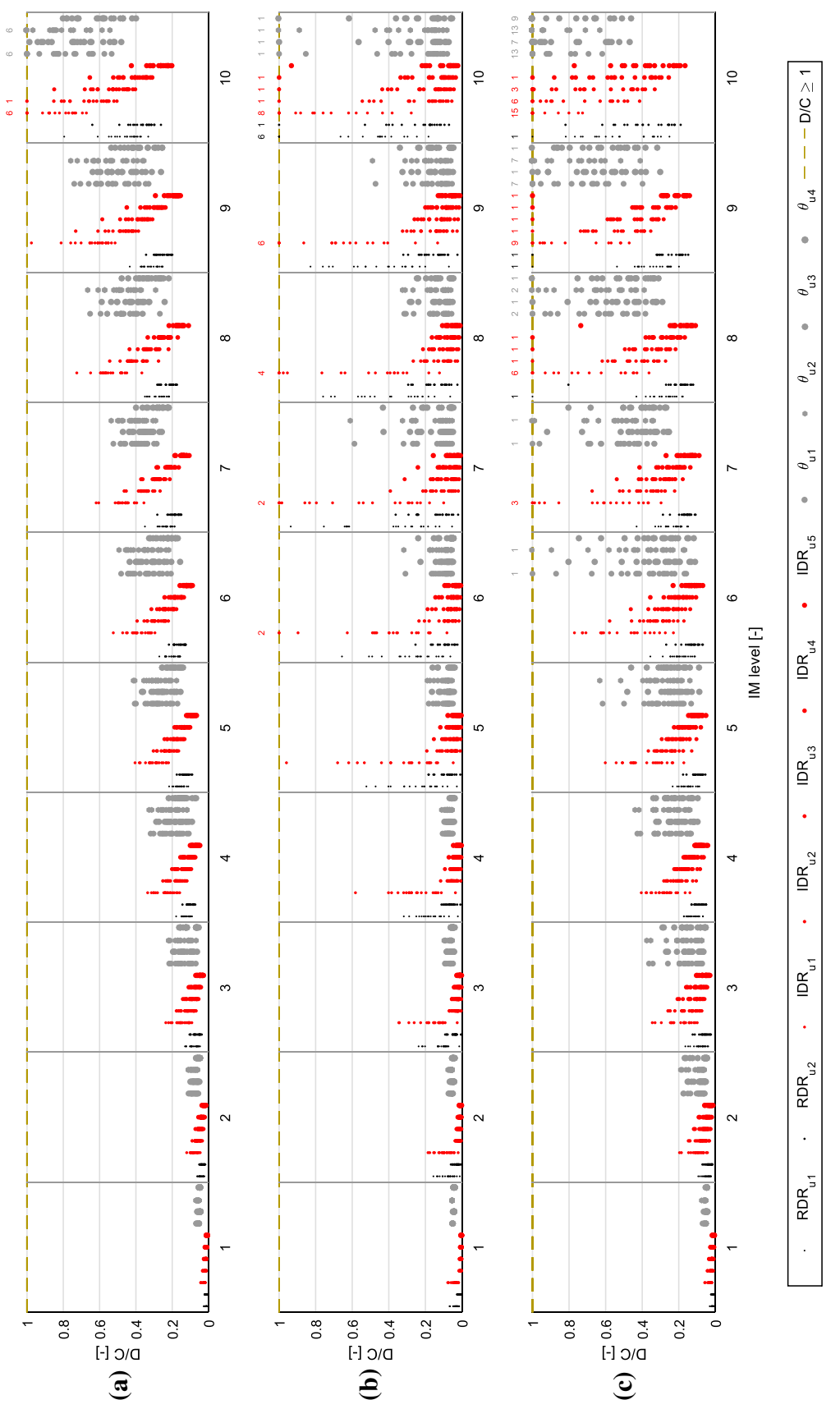

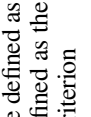

워웡

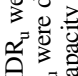

要

密能

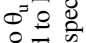

要券

要表

裉

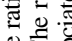

토

क.

界

쿤

동 흉

용

등

我要

들

둥

记

के

क

在.

응 은

흐

흘 흥

ฐึ

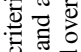

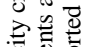

क्ष

ฮै

这考

害

ส 을

品

흘

总

记 홍

을

政

글

论

응

츨

ฮै 을

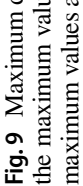

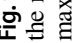




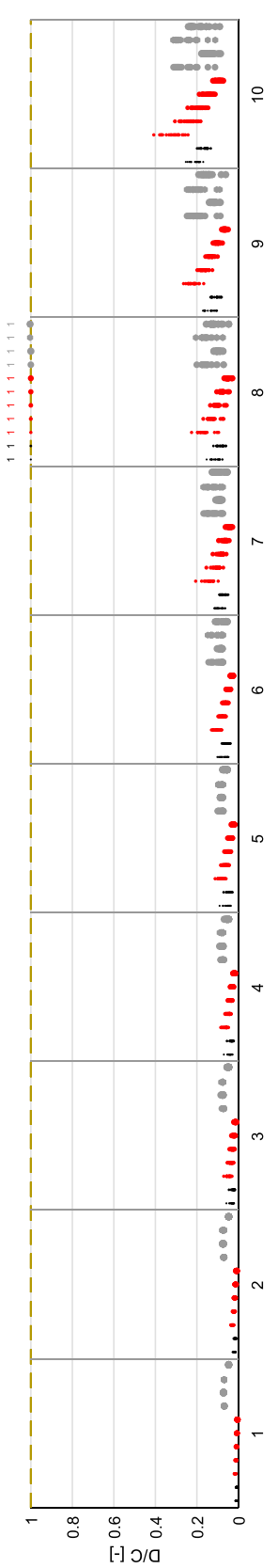

త

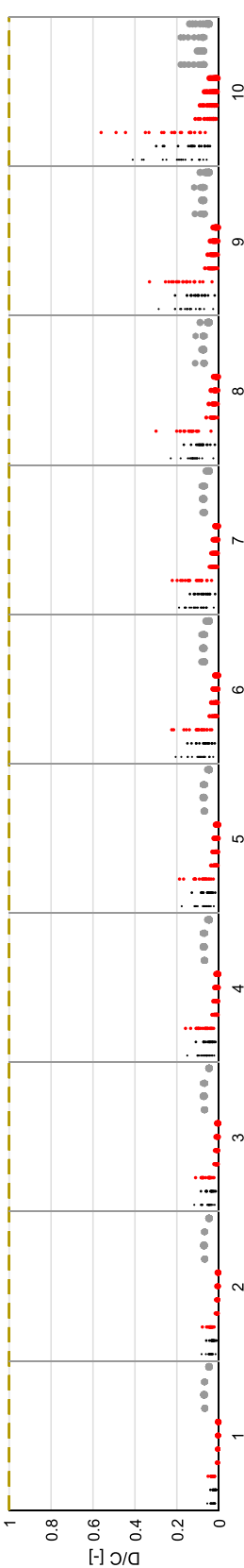

$\hat{e}$

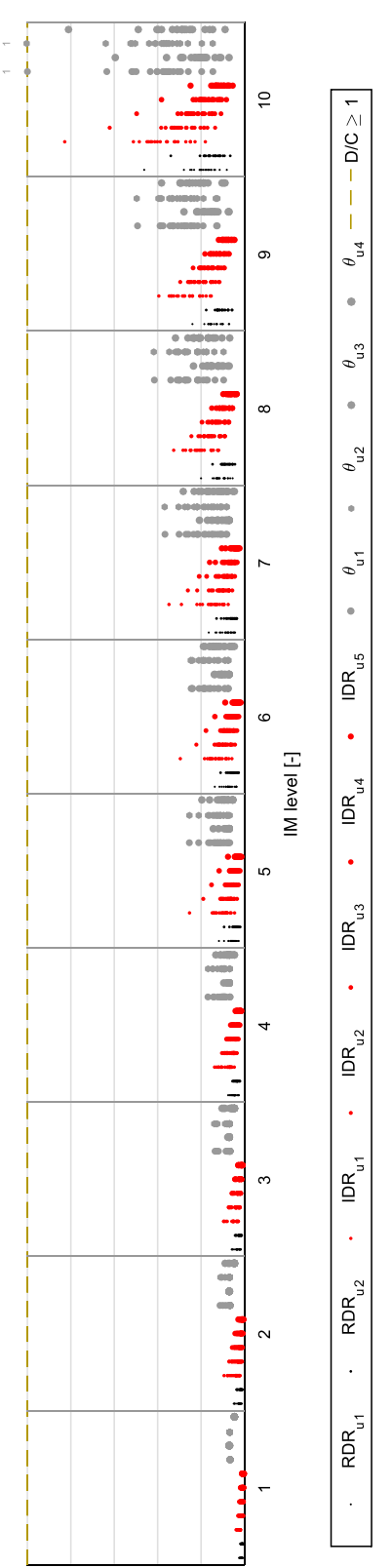

哥 옳

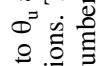

政 密鹤 ज。 흥 象 옹 훔

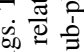
至 窟: 元 낭 可

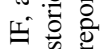
름 एक * 을 들 蛘 结令 $\circ$ उั) 흉 离焉 륭 寻 원 তี 跑 ขอ 공

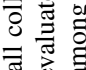
of of os

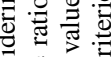
○ิ $\Xi$ U 이 当 ఏ き 。ै స్ ते च क

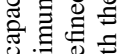
ช 艺

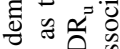
궁

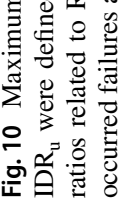


Table 5 Collapse occurrences $N_{C O}, N_{C l}$, and $N_{C T}$ related to chord rotation capacities $\theta_{u}$ for each element type of all AQ site buildings and corresponding to IM levels 9 and 10

\begin{tabular}{|c|c|c|c|c|c|}
\hline \multirow{3}{*}{$\begin{array}{l}\text { IM level, } \\
\text { building } \\
\text { type, } \theta_{\mathrm{u}} \\
\text { criterion }\end{array}$} & \multicolumn{4}{|c|}{$\mathrm{N}_{\mathrm{C} 0}[-]\left(\mathrm{N}_{\mathrm{C} 1}[-]\right)$} & \multirow[t]{3}{*}{$\mathrm{N}_{\mathrm{CT}}[-]$} \\
\hline & \multicolumn{2}{|c|}{$\begin{array}{l}\text { Frame element } \\
\text { types }\end{array}$} & \multicolumn{2}{|c|}{ Stairwell element types } & \\
\hline & Columns & Beams & Short columns & Beams & \\
\hline \multicolumn{6}{|l|}{ IM level 9} \\
\hline \multicolumn{6}{|l|}{$\mathrm{BF}$} \\
\hline$\theta_{\mathrm{u} 1}$ & $2(0)$ & $3(1)$ & $9(4)$ & $5(0)$ & 10 \\
\hline$\theta_{\mathrm{u} 2}$ & $1(0)$ & $2(0)$ & $2(0)$ & $7(5)$ & 7 \\
\hline$\theta_{\mathrm{u} 3}$ & $3(0)$ & $4(0)$ & $10(4)$ & $6(0)$ & 11 \\
\hline$\theta_{\mathrm{u} 4}$ & $1(0)$ & $1(0)$ & $2(0)$ & $2(0)$ & 2 \\
\hline \multicolumn{6}{|l|}{ IF } \\
\hline$\theta_{\mathrm{u} 1}$ & $4(0)$ & $4(0)$ & $8(3)$ & $4(0)$ & 8 \\
\hline$\theta_{\mathrm{u} 2}$ & $2(0)$ & $2(0)$ & $4(0)$ & $4(0)$ & 4 \\
\hline$\theta_{\mathrm{u} 3}$ & $4(0)$ & $5(0)$ & $9(3)$ & $5(0)$ & 9 \\
\hline$\theta_{\mathrm{u} 4}$ & $2(0)$ & $2(0)$ & $4(0)$ & $4(0)$ & 4 \\
\hline \multicolumn{6}{|l|}{$\mathrm{PF}$} \\
\hline$\theta_{\mathrm{u} 1}$ & $11(0)$ & $11(0)$ & $17(6)$ & $10(0)$ & 17 \\
\hline$\theta_{\mathrm{u} 2}$ & $6(0)$ & $6(0)$ & $8(0)$ & $12(4)$ & 12 \\
\hline$\theta_{\mathrm{u} 3}$ & $11(0)$ & $12(0)$ & $17(0)$ & $10(0)$ & 17 \\
\hline$\theta_{\mathrm{u} 4}$ & $7(0)$ & $6(0)$ & $8(0)$ & $8(0)$ & 8 \\
\hline \multicolumn{6}{|c|}{ IM level 10} \\
\hline \multicolumn{6}{|c|}{$\mathrm{BF}$} \\
\hline$\theta_{\mathrm{u} 1}$ & $20(0)$ & $20(0)$ & $20(0)$ & $19(0)$ & 20 \\
\hline$\theta_{\mathrm{u} 2}$ & $9(0)$ & $12(0)$ & $18(0)$ & $20(0)$ & 20 \\
\hline$\theta_{\mathrm{u} 3}$ & $20(0)$ & $20(0)$ & $20(0)$ & $19(0)$ & 20 \\
\hline$\theta_{\mathrm{u} 4}$ & $11(0)$ & $12(1)$ & $13(0)$ & $12(0)$ & 15 \\
\hline \multicolumn{6}{|l|}{ IF } \\
\hline$\theta_{\mathrm{u} 1}$ & $10(0)$ & $9(0)$ & $13(2)$ & $11(0)$ & 14 \\
\hline$\theta_{\mathrm{u} 2}$ & $8(0)$ & $9(0)$ & $9(0)$ & $13(3)$ & 14 \\
\hline$\theta_{\mathrm{u} 3}$ & $10(0)$ & $10(0)$ & $13(1)$ & $13(0)$ & 14 \\
\hline$\theta_{\mathrm{u} 4}$ & $8(0)$ & $9(1)$ & 7 (1) & $8(0)$ & 10 \\
\hline \multicolumn{6}{|l|}{$\mathrm{PF}$} \\
\hline$\theta_{\mathrm{u} 1}$ & $18(0)$ & $18(0)$ & $19(0)$ & $19(0)$ & 19 \\
\hline$\theta_{\mathrm{u} 2}$ & $17(0)$ & $18(0)$ & $18(0)$ & $19(0)$ & 19 \\
\hline$\theta_{\mathrm{u} 3}$ & $18(0)$ & $18(0)$ & $19(0)$ & $19(0)$ & 19 \\
\hline$\theta_{\mathrm{u} 4}$ & $17(0)$ & $18(0)$ & $17(0)$ & $18(0)$ & 18 \\
\hline
\end{tabular}

in 50 years for the considered site and soil condition, i.e., $S a\left(T_{1}\right)_{2 / 50}$ and $S a\left(T_{1}\right)_{5 / 50}$, are also reported; they are related to return period $T_{R}$ equal to 2475 and 975 years, respectively. The $2 \%$ limit (near collapse limit state NCLS) was recommended by Eurocode (CEN 2005), US codes (e.g., Luco et al. 2007), and this is widely used in the literature (Goulet et al. 2007; Haselton et al. 2011), whereas the 5\% (collapse prevention limit state, SLC in Italian) one was reported by the Italian NTC 2008 (CS.LL.PP. 2008). In particular, the hazard parameters were derived from the database provided by Meletti and Montaldo (2007), and the spectral accelerations were compliant with the Italian NTC 2008 design spectra (CS. 

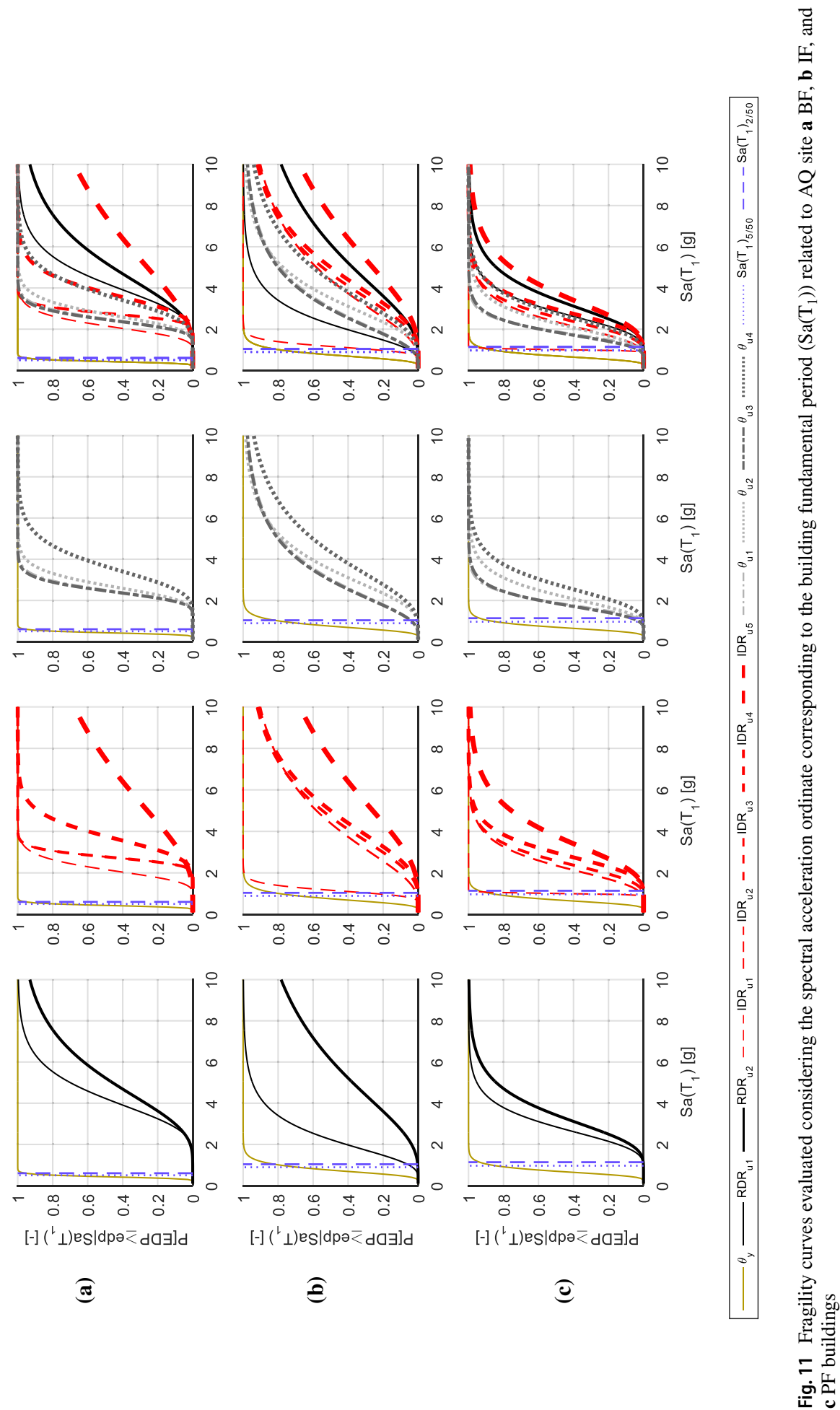

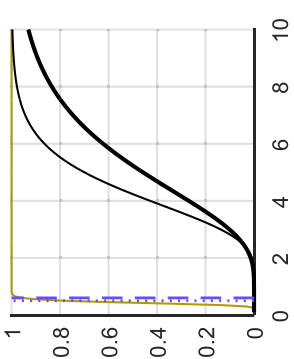

$\left.[-]\left({ }^{L} \perp\right) e s \mid d p a \overline{<} d 0 \exists\right] d$

ङ
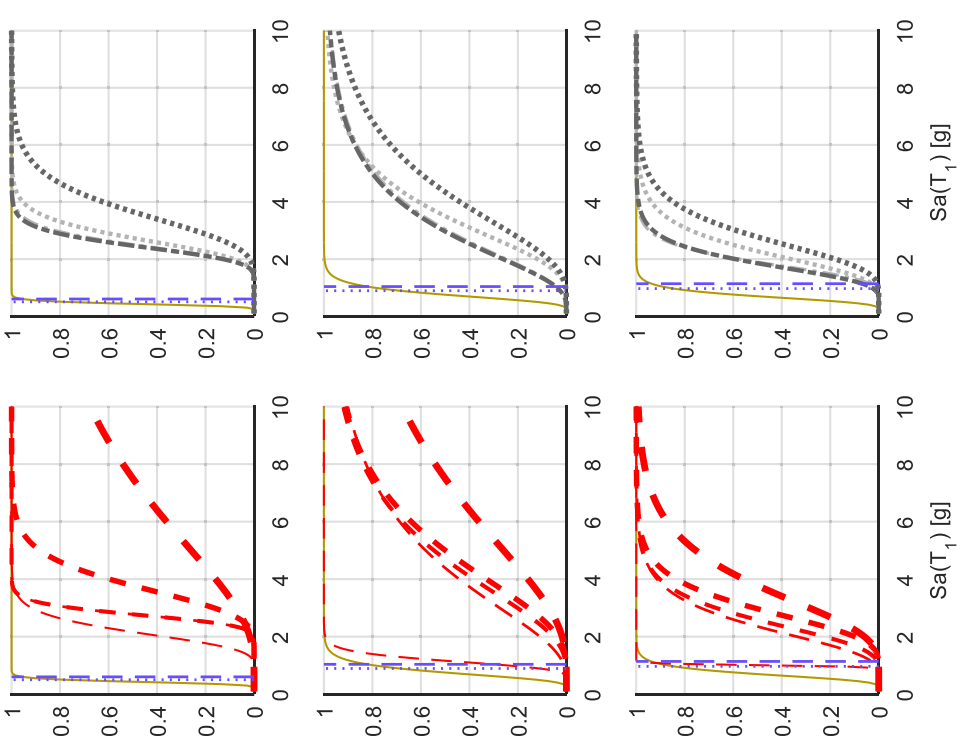

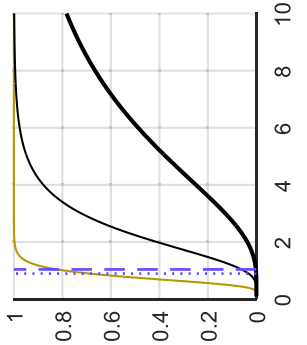

$\left.[-]\left({ }^{l} \perp\right) e s \mid d p a<d a j\right] d$

อ

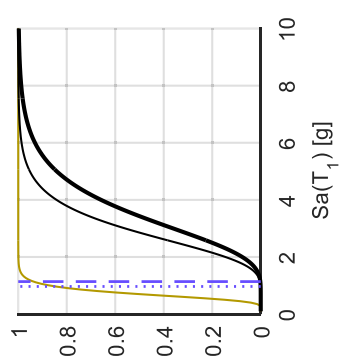

$\left.[-]\left({ }^{l} \perp\right) e s \mid d p a \overline{<} d a \exists\right] d$

e

$\infty$

.

$\varangle$

离

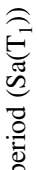

政

$\stackrel{8}{=}$

章

.

రั0

㺃

$\stackrel{0}{0}$

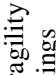

雳鄫

$=\Xi$

운 
Table 6 Fragility median $(m)$ and (record-to-record) logarithmic standard deviation $(\beta)$ related to AQ site buildings for all considered capacity criteria

\begin{tabular}{|c|c|c|c|c|c|c|}
\hline \multirow[t]{2}{*}{ Capacity criterion } & \multicolumn{3}{|l|}{ m (g) } & \multicolumn{3}{|l|}{$\beta(-)$} \\
\hline & BF & IF & PF & BF & IF & PF \\
\hline$\theta_{\mathrm{y}}$ & 0.432 & 0.752 & 0.699 & 0.193 & 0.349 & 0.318 \\
\hline $\mathrm{RDR}_{\mathrm{u} 1}$ & 4.236 & 2.239 & 2.853 & 0.317 & 0.497 & 0.337 \\
\hline $\mathrm{RDR}_{\mathrm{u} 2}$ & 5.235 & 6.119 & 3.429 & 0.437 & 0.628 & 0.377 \\
\hline $\mathrm{IDR}_{\mathrm{u} 1}$ & 2.162 & 1.163 & 1.009 & 0.236 & 0.216 & 0.045 \\
\hline $\mathrm{IDR}_{\mathrm{u} 2}$ & 2.776 & 4.390 & 2.354 & 0.116 & 0.638 & 0.387 \\
\hline $\mathrm{IDR}_{\mathrm{u} 3}$ & 2.776 & 4.697 & 2.584 & 0.116 & 0.538 & 0.337 \\
\hline $\mathrm{IDR}_{\mathrm{u} 4}$ & 3.775 & 5.005 & 2.968 & 0.236 & 0.508 & 0.307 \\
\hline $\mathrm{IDR}_{\mathrm{u} 5}$ & 7.502 & 7.502 & 3.775 & 0.628 & 0.628 & 0.407 \\
\hline$\theta_{\mathrm{u} 1}$ & 2.507 & 3.045 & 1.893 & 0.196 & 0.618 & 0.286 \\
\hline$\theta_{\mathrm{u} 2}$ & 2.738 & 3.506 & 2.277 & 0.226 & 0.477 & 0.367 \\
\hline$\theta_{\mathrm{u} 3}$ & 2.469 & 2.968 & 1.854 & 0.186 & 0.618 & 0.327 \\
\hline$\theta_{\mathrm{u} 4}$ & 3.660 & 4.352 & 2.776 & 0.286 & 0.538 & 0.357 \\
\hline
\end{tabular}

LL.PP. 2008). The fragility curves related to the yielding limit of the buildings are also reported in Fig. 11. This condition was defined by considering the earliest achievement of the yielding chord rotation $\theta_{y}$ (defined in Eq. 4.2) by at least one member section end.

As a first comment, the yielding limit of the building was found to be consistent with the collapse seismic demand in terms of $S a\left(T_{1}\right)_{2 / 50}$ and $S a\left(T_{1}\right)_{5 / 50}$. As a matter of fact, for all building typologies (and AQ site) the collapse demand was associated with a high and very high probability of yielding initiation (e.g., larger than 75 and 95\%). This confirms the consistency of the code-conforming building design since the building exhibit an inelastic behavior under normative collapse demands.

$\mathrm{PF}$ is more critical than $\mathrm{BF}$ and IF for all capacity criteria, whereas the relative discrepancies depend on the considered capacity criterion for the other building typologies. In fact, the different capacities produced quite spread fragilities for the different building typologies. This was particularly evident for IF buildings, for which the median fragility $S a\left(T_{1}\right)$ ranged between 1.2 and $6.0 \mathrm{~g}$. $\mathrm{IDR}_{\mathrm{u} 1}$ and $\mathrm{IDR}_{\mathrm{u} 5}$ produced the highest and lowest fragility for all building typologies, respectively, where higher fragility is meant as larger exceedance probability values for given IM thresholds, or equivalently, lower IM values for given exceedance probability thresholds. It is recalled that $\mathrm{IDR}_{\mathrm{u} 5}$ is expected to be more representative of sidesway-like conditions, and this is also consistent with the estimated fragilities. It is worth noting that $\mathrm{RDR}_{\mathrm{u} 2}$ follows $\mathrm{IDR}_{\mathrm{u} 5}$ in terms of higher fragility, and this also agrees with the nature of the former criterion (50\% shear strength drop in PO curve from the peak value). The discrepancy between $\mathrm{RDR}_{\mathrm{u} 2}$ and $\mathrm{IDR}_{\mathrm{u} 5}$ fragility curves is relatively reduced for $\mathrm{PF}$ and relatively significant for $\mathrm{BF}$, whereas it has an intermediate value for IF.

For IF and PF, a large fragility discrepancy between $\operatorname{IDR}_{\mathrm{u} 1}$ and the other $\operatorname{IDR}_{\mathrm{u}}$ capacities was observed, whereas this was minor for BF. It is recalled that $\mathrm{IDR}_{\mathrm{u} 1}$ is quite reduced for infilled inter-stories if compared to the other $\mathrm{IDR}_{\mathrm{u}}$ thresholds, whereas it is more comparable to these latter for bare stories. $\mathrm{IDR}_{\mathrm{u} 1}$ is certainly very conservative (especially for IF and PF), and it relates to an early plastic global response of the building, especially for IF and PF buildings, as it can be seen by comparing the yielding limit fragility and the $\mathrm{IDR}_{\mathrm{u} 1}$ collapse fragility curves. On the other side, $\mathrm{RDR}_{\mathrm{u} 2}$ and $\mathrm{IDR}_{\mathrm{u} 5}$ correspond to a more 
significant plastic (degradation) response, and it likely supplies quite reduced safety margins with regard to global collapse. $\theta_{u 4}$ produced fragilities lower than the other $\theta_{u}$ ones for all building typologies, whereas these latter were more comparable among them, with $\theta_{u 2}$ fragility slightly lower than the empirical ones. Indeed, the general conservativeness of the empirical formulations is highlighted. The $\mathrm{IDR}_{\mathrm{u} 2}$ to $\mathrm{IDR}_{\mathrm{u} 4}$ fragility range matches quite well the $\theta_{u}$ ones for $\mathrm{BF}$, while it is relatively centered on the $\theta_{u 4}$ curve for both IF and $\mathrm{PF}$. In particular, $\theta_{u 4}$ is associated with fragility very similar to the $\mathrm{IDR}_{\mathrm{u} 4}$ one for all building typologies (especially for $\mathrm{BF}$ and $\mathrm{PF}$ ), which is still relatively distanced from $\mathrm{RDR}_{\mathrm{u} 2}$ and $\mathrm{IDR}_{\mathrm{u} 5}$ curves. This evidence suggests that, regardless of the different building typologies (i.e., $\mathrm{BF}, \mathrm{IF}$, and $\mathrm{PF}$ ), $\mathrm{IDR}_{\mathrm{u} 4}$ is consistent with a relevant incursion into the inelastic response (e.g., onset of local collapse processes) even though still far from heavy softening $\left(\mathrm{RDR}_{\mathrm{u} 2}\right)$ and sidesway-like collapse $\left(\mathrm{IDR}_{\mathrm{u} 5}\right)$. More quantitative details on this aspect will be discussed in the following sections.

\subsection{Collapse performance}

Figure 12 shows the estimated collapse margin ratios $Z_{2 / 50}$ and $Z_{5 / 50}$ and the conditional collapse probabilities (considering record-to-record uncertainty $\beta$ ) larger than $0.09 \%$ for all capacity criteria related to AQ (a) BF, (b) IF, and (c) PF. Overall, the margin ratios are relatively large (low) for $\mathrm{BF}(\mathrm{PF})$. IF ratios are intermediate between $\mathrm{BF}$ and $\mathrm{PF}$, except for $\mathrm{RDR}_{\mathrm{u} 1}$ and $\mathrm{IDR}_{\mathrm{u} 1}$, which are as critical as the PF ones. Figure 12 stresses the severity of $\mathrm{IDR}_{\mathrm{u} 1}\left(\mathrm{RDR}_{\mathrm{u} 1}\right)$ for both IF and PF (IF): very critical collapse margin ratios and

(a)

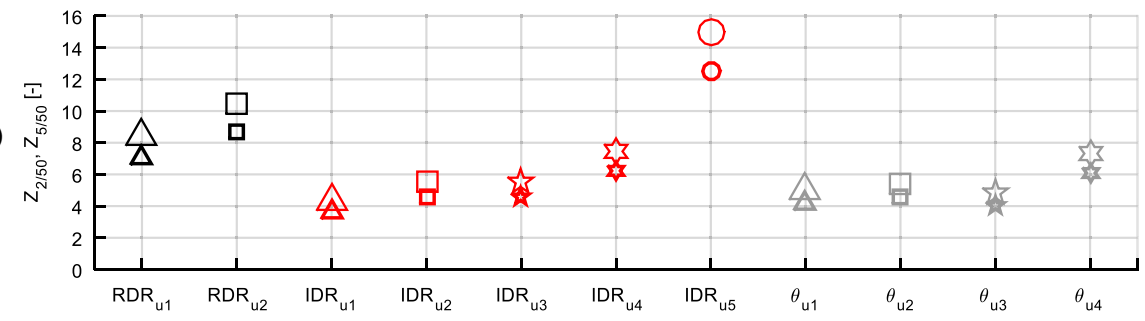

(b)

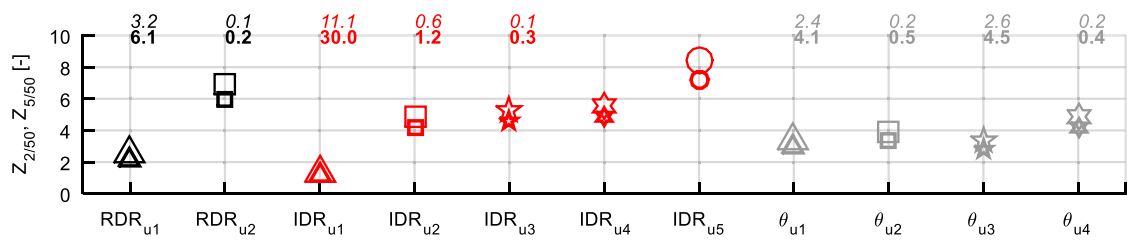

(c)

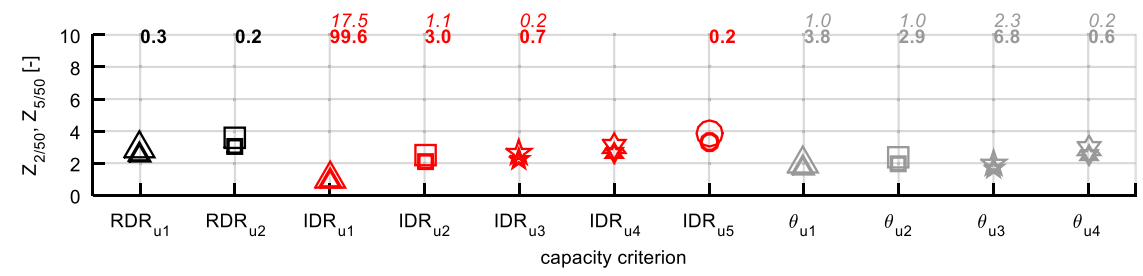

Fig. 12 Collapse margin ratios $Z_{2 / 50}$ (small thick markers) and $Z_{5 / 50}$ (large thin markers) for all considered capacity criteria related to $\mathrm{AQ}$ a $\mathrm{BF}, \mathbf{b} \mathrm{IF}$, and $\mathbf{c}$ PF buildings. The conditional collapse probabilities larger than $0.09 \%$ are reported (in \%) at the top of each figure for each criterion; the inferior number (in bold) is related to $S a\left(T_{1}\right)_{2 / 50}$ and the superior one (in italic) to $S a\left(T_{1}\right)_{5 / 50}$ 
probabilities were found. The relatively critical condition related to $\mathrm{RDR}_{\mathrm{u} 1}$ was mainly due to the low $\mathrm{RDR}_{\mathrm{u} 1}$ capacity, which was associated with large elastic stiffness and the heavy softening over the early post-yield branch (e.g., Ricci et al. 2018). Considering all criteria but $\mathrm{IDR}_{\mathrm{u} 1}$, the collapse capacity margin ratios (collapse probabilities) are larger (smaller) than the ones found by Haselton et al. (2011) and Noh and Tesfamariam (2018). The collapse margin ratio associated with $\mathrm{IDR}_{\mathrm{u} 5}$, which is likely to be the most adherent to sidesway-like collapse, is extremely high for BF (e.g., larger than 12), high for IF (e.g., larger than 7) and relatively reduced for PF (e.g., larger than 3). For PF, IF, and BF, the collapse margin ratio related to $\mathrm{IDR}_{\mathrm{u} 5}$ is quite similar, mildly larger, and significantly larger than the one associated with $\mathrm{RDR}_{\mathrm{u} 2}$, respectively. This highlights that the safety associated with heavy plastic incursion and global softening response (e.g., $\mathrm{RDR}_{\mathrm{u} 2}$ ) significantly depends on the building typology, and this is similar to, mildly larger, and significantly larger than the one associated with a sidesway-like collapse $\left(\mathrm{IDR}_{\mathrm{u}}\right)$ for PF, IF, and BF buildings.

Despite the extreme conservativeness of $\mathrm{IDR}_{\mathrm{u} 1}$, the collapse probability related to this criterion significantly exceeded $\bar{P}_{c}$ only for IF using $S a\left(T_{1}\right)_{2 / 50}$ and for PF. In fact,

Table 7 Collapse performance assessment related to AQ BF, IF, and PF buildings: acceptable collapse margin ratio $(\overline{\mathrm{Z}})$ and collapse margin ratios $\left(\mathrm{Z}_{2 / 50}\right.$ and $\left.\mathrm{Z}_{5 / 50}\right)$ to $\overline{\mathrm{Z}}$ ratios evaluated considering record-to-record uncertainty $(\beta)$ and total uncertainty $\left(\beta_{\text {TOT }}\right)$

\begin{tabular}{|c|c|c|c|c|c|c|c|c|c|}
\hline \multirow[t]{3}{*}{ Capacity criterion } & \multicolumn{3}{|l|}{$\bar{Z} \mid \beta(-)$} & \multirow{2}{*}{\multicolumn{3}{|c|}{$\frac{\frac{L_{2 / 50}}{\bar{Z}} \mid \beta(-)}{\left(\frac{Z_{2 / 50}}{\bar{Z}} \mid \beta_{T O T}(-)\right)}$}} & \multirow{2}{*}{\multicolumn{3}{|c|}{$\frac{\frac{Z_{5 / 50}}{\bar{Z}} \mid \beta(-)}{\left(\frac{Z_{5 / 50}}{\bar{Z}} \mid \beta_{T O T}(-)\right)}$}} \\
\hline & \multicolumn{3}{|c|}{$\left(\bar{Z} \mid \beta_{T O T}(-)\right)$} & & & & & & \\
\hline & BF & IF & PF & $\overline{\mathrm{BF}}$ & IF & $\mathrm{PF}$ & $\mathrm{BF}$ & IF & PF \\
\hline $\mathrm{RDR}_{\mathrm{u} 1}$ & $\begin{array}{c}1.500 \\
(2.181)\end{array}$ & $\begin{array}{c}1.892 \\
(2.514)\end{array}$ & $\begin{array}{c}1.539 \\
(2.211)\end{array}$ & $\begin{array}{c}4.685 \\
(3.223)\end{array}$ & $\begin{array}{c}1.139 \\
(0.857)\end{array}$ & $\begin{array}{c}1.628 \\
(1.134)\end{array}$ & $\begin{array}{c}5.617 \\
(3.864)\end{array}$ & $\begin{array}{c}1.326 \\
(0.997)\end{array}$ & $\begin{array}{r}1.916 \\
(1.334)\end{array}$ \\
\hline $\mathrm{RDR}_{\mathrm{u} 2}$ & $\begin{array}{c}1.751 \\
(2.388)\end{array}$ & $\begin{array}{c}2.237 \\
(2.843)\end{array}$ & $\begin{array}{c}1.621 \\
(2.276)\end{array}$ & $\begin{array}{c}4.960 \\
(3.638)\end{array}$ & $\begin{array}{c}2.634 \\
(2.073)\end{array}$ & $\begin{array}{c}1.859 \\
(1.324)\end{array}$ & $\begin{array}{c}5.947 \\
(4.362)\end{array}$ & $\begin{array}{c}3.065 \\
(2.411)\end{array}$ & $\begin{array}{r}2.187 \\
(1.557)\end{array}$ \\
\hline $\mathrm{IDR}_{\mathrm{u} 1}$ & $\begin{array}{c}1.353 \\
(2.078)\end{array}$ & $\begin{array}{c}1.319 \\
(2.057)\end{array}$ & $\begin{array}{c}1.060 \\
(1.951)\end{array}$ & $\begin{array}{c}2.650 \\
(1.726)\end{array}$ & $\begin{array}{c}0.849 \\
(0.544)\end{array}$ & $\begin{array}{c}0.837 \\
(0.454)\end{array}$ & $\begin{array}{c}3.177 \\
(2.069)\end{array}$ & $\begin{array}{c}0.988 \\
(0.633)\end{array}$ & $\begin{array}{r}0.984 \\
(0.535)\end{array}$ \\
\hline $\mathrm{IDR}_{\mathrm{u} 2}$ & $\begin{array}{c}1.160 \\
(1.978)\end{array}$ & $\begin{array}{c}2.266 \\
(2.871)\end{array}$ & $\begin{array}{c}1.642 \\
(2.294)\end{array}$ & $\begin{array}{c}3.972 \\
(2.329)\end{array}$ & $\begin{array}{c}1.866 \\
(1.472)\end{array}$ & $\begin{array}{c}1.260 \\
(0.902)\end{array}$ & $\begin{array}{c}4.763 \\
(2.792)\end{array}$ & $\begin{array}{c}2.171 \\
(1.713)\end{array}$ & $\begin{array}{c}1.482 \\
(1.061)\end{array}$ \\
\hline $\mathrm{IDR}_{\mathrm{u} 3}$ & $\begin{array}{c}1.160 \\
(1.978)\end{array}$ & $\begin{array}{c}1.992 \\
(2.607)\end{array}$ & $\begin{array}{c}1.539 \\
(2.211)\end{array}$ & $\begin{array}{c}3.972 \\
(2.329)\end{array}$ & $\begin{array}{c}2.271 \\
(1.735)\end{array}$ & $\begin{array}{c}1.475 \\
(1.027)\end{array}$ & $\begin{array}{c}4.763 \\
(2.792)\end{array}$ & $\begin{array}{c}2.642 \\
(2.018)\end{array}$ & $\begin{array}{c}1.735 \\
(1.208)\end{array}$ \\
\hline $\mathrm{IDR}_{\mathrm{u} 4}$ & $\begin{array}{c}1.353 \\
(2.078)\end{array}$ & $\begin{array}{c}1.916 \\
(2.537)\end{array}$ & $\begin{array}{c}1.481 \\
(2.167)\end{array}$ & $\begin{array}{c}4.628 \\
(3.014)\end{array}$ & $\begin{array}{c}2.515 \\
(1.900)\end{array}$ & $\begin{array}{c}1.761 \\
(1.204)\end{array}$ & $\begin{array}{c}5.549 \\
(3.614)\end{array}$ & $\begin{array}{c}2.926 \\
(2.210)\end{array}$ & $\begin{array}{c}2.072 \\
(1.416)\end{array}$ \\
\hline $\mathrm{IDR}_{\mathrm{u} 5}$ & $\begin{array}{c}2.237 \\
(2.843)\end{array}$ & $\begin{array}{c}2.237 \\
(2.843)\end{array}$ & $\begin{array}{c}1.685 \\
(2.330)\end{array}$ & $\begin{array}{c}5.565 \\
(4.379)\end{array}$ & $\begin{array}{c}3.230 \\
(2.541)\end{array}$ & $\begin{array}{c}1.969 \\
(1.424)\end{array}$ & $\begin{array}{c}6.672 \\
(5.250)\end{array}$ & $\begin{array}{c}3.757 \\
(2.956)\end{array}$ & $\begin{array}{r}2.316 \\
(1.675)\end{array}$ \\
\hline$\theta_{\mathrm{u} 1}$ & $\begin{array}{c}1.285 \\
(2.037)\end{array}$ & $\begin{array}{c}2.208 \\
(2.815)\end{array}$ & $\begin{array}{c}1.443 \\
(2.139)\end{array}$ & $\begin{array}{c}3.236 \\
(2.042)\end{array}$ & $\begin{array}{c}1.328 \\
(1.042)\end{array}$ & $\begin{array}{c}1.152 \\
(0.777)\end{array}$ & $\begin{array}{c}3.880 \\
(2.448)\end{array}$ & $\begin{array}{c}1.545 \\
(1.212)\end{array}$ & $\begin{array}{r}1.355 \\
(0.915)\end{array}$ \\
\hline$\theta_{\mathrm{u} 2}$ & $\begin{array}{c}1.336 \\
(2.067)\end{array}$ & $\begin{array}{c}1.844 \\
(2.470)\end{array}$ & $\begin{array}{c}1.600 \\
(2.259)\end{array}$ & $\begin{array}{c}3.400 \\
(2.197)\end{array}$ & $\begin{array}{c}1.831 \\
(1.367)\end{array}$ & $\begin{array}{c}1.250 \\
(0.885)\end{array}$ & $\begin{array}{c}4.076 \\
(2.635)\end{array}$ & $\begin{array}{c}2.130 \\
(1.590)\end{array}$ & $\begin{array}{r}1.471 \\
(1.042)\end{array}$ \\
\hline$\theta_{\mathrm{u} 3}$ & $\begin{array}{c}1.269 \\
(2.028)\end{array}$ & $\begin{array}{c}2.208 \\
(2.815)\end{array}$ & $\begin{array}{c}1.520 \\
(2.196)\end{array}$ & $\begin{array}{c}3.228 \\
(2.020)\end{array}$ & $\begin{array}{c}1.295 \\
(1.016)\end{array}$ & $\begin{array}{c}1.072 \\
(0.742)\end{array}$ & $\begin{array}{c}3.870 \\
(2.421)\end{array}$ & $\begin{array}{c}1.506 \\
(1.181)\end{array}$ & $\begin{array}{r}1.261 \\
(0.873)\end{array}$ \\
\hline$\theta_{\mathrm{u} 4}$ & $\begin{array}{c}1.443 \\
(2.139)\end{array}$ & $\begin{array}{c}1.992 \\
(2.607)\end{array}$ & $\begin{array}{c}1.580 \\
(2.243)\end{array}$ & $\begin{array}{c}4.207 \\
(2.839)\end{array}$ & $\begin{array}{c}2.104 \\
(1.607)\end{array}$ & $\begin{array}{c}1.544 \\
(1.088)\end{array}$ & $\begin{array}{c}5.044 \\
(3.404)\end{array}$ & $\begin{array}{c}2.447 \\
(1.870)\end{array}$ & $\begin{array}{r}1.817 \\
(1.280)\end{array}$ \\
\hline
\end{tabular}

$\overline{\mathrm{Z}}$ was assessed considering target collapse probability $\bar{P}_{c}$ equal to $10 \%$ 
the collapse probability just exceeded $\bar{P}_{c}$ for IF using $S a\left(T_{1}\right)_{5 / 50}$ and was below $0.09 \%$ for BF. Considering all criteria but $\mathrm{IDR}_{\mathrm{u} 1}$, the collapse probabilities are significantly far below the target value ( $\bar{P}_{c}$ equal to $10 \%$ ), as it can be seen in Fig. $12 . \mathrm{RDR}_{\mathrm{u} 1}, \theta_{u 1}$, and $\theta_{u 3}$ related to IF and $\theta_{u 3}$ related to PF exhibit the largest collapse probabilities, which are still significantly lower than $\bar{P}$.

Table 7 reports the results of the collapse margin assessment. In particular, the acceptable collapse margin ratios $(\bar{Z})$ and collapse margin to acceptable margin ratios $\left(\mathrm{Z}_{2 / 50} / \overline{\mathrm{Z}}\right)$ and $\left.\mathrm{Z}_{5 / 50} / \overline{\mathrm{Z}}\right)$ are reported considering both record-to-record uncertainty $\beta$ and total uncertainty $\beta_{\text {TOT }}$. The results related to $\mathrm{RDR}_{\mathrm{u} 2}$ and $\mathrm{IDR}_{\mathrm{u} 5}$ are highlighted according to the nature of these capacity criteria: both $Z_{2 / 50} / \bar{Z}$ and $Z_{5 / 50} / \bar{Z}$ related to $\mathrm{BF}$ are extremely large (e.g., larger than 3.5-4), and this stresses the excessive conservativeness of the design prescription for this building typology. The ratios associated with PF are significantly lower than the BF ones, but still (slightly) larger than the unity. This might suggest that despite the critical performance of PF buildings, the safety conditions are still satisfactory, even though with relatively reduced margin ratios. The ratios related to IF buildings have an intermediate value between BF and PF (e.g., larger than 2.5-3). It is recalled that the reported results are related to AQ site buildings, which are associated with the highest hazard conditions (and with the strictest design prescriptions). The collapse margin to acceptable margin ratios related to the other criteria quantify the correlations between the building safety and the different nature of the criteria. These values are reported in the paper for comparison purposes, and further comments on these values are omitted for the sake of brevity. Since the present work is not focused on the influence of the building typology on the collapse but addresses the influence of the different capacity criteria, further details and comments on the former aspects are also omitted.

(a)

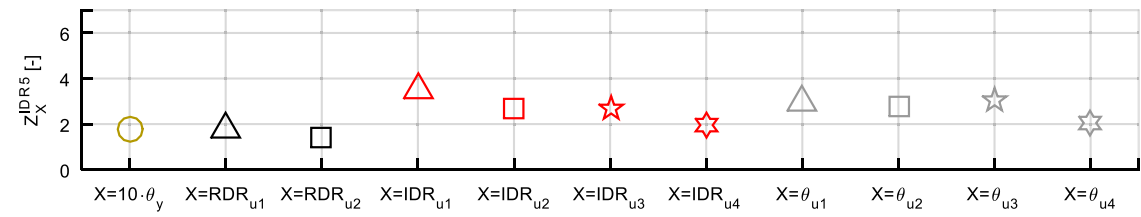

(b)

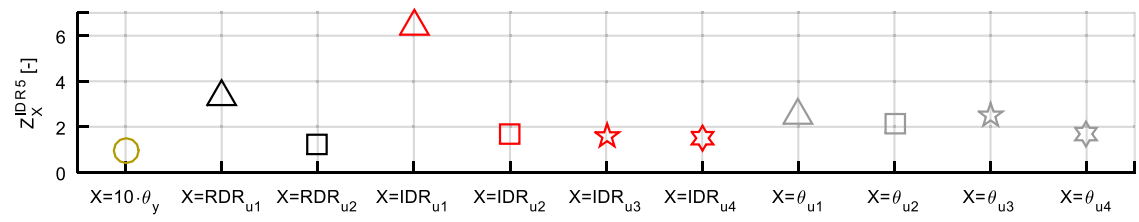

(c)

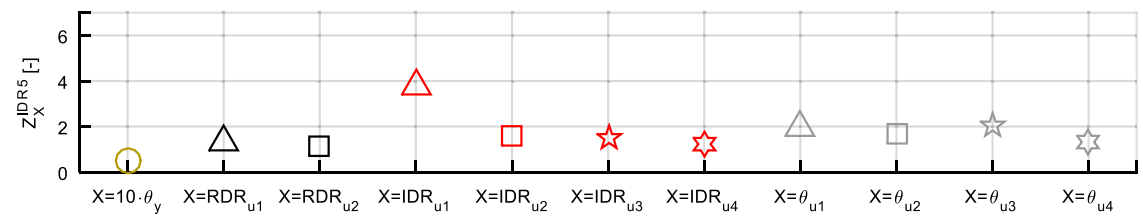

Fig. 13 Inter-capacity margin ratios $Z_{X}^{Y}$ computed considering $\mathrm{Y}=\mathrm{IDR}_{\mathrm{u} 5}$ (i.e., $Z_{X}^{I D R 5}$ ) related to $\mathrm{AQ}$ a $\mathrm{BF}, \mathbf{b}$ $\mathrm{IF}$, and $\mathbf{c} \mathrm{PF}$ buildings 


\subsection{Inter-capacity margin ratios}

$\mathrm{Z}_{X}^{Y}$ was computed considering $\mathrm{Y}$ equal to $\operatorname{IDR}_{\mathrm{u} 5}$ (i.e., $Z_{X}^{I D R u 5}$ ) and $\mathrm{X}$ equal to all capacity criteria for AQ (a) BF, (b) IF, and (c) PF buildings (Fig. 13). $Z_{X}^{I D R u 5}$ identifies the building capacity from the $\mathrm{X}$ criterion capacity to the most adherent to the sidesway collapse. Depending on the specific $X$ criterion, $Z_{X}^{I D R u} 5$ provides useful information on the building response associated with the peculiar criterion characteristics. For example, $Z_{\theta y}^{I D R u}$ defines the margin capacity corresponding to the whole post-elastic building response: a larger (smaller) value can be representative of a system that develops a more (less) significant resistance from the first yielding to the global collapse. Analogously, $Z_{\theta u}^{I D R u 5}$ identifies the margin capacity corresponding to the local to sidesway-like collapse development. $Z_{\theta y}^{I D R u}$ supplies quantitative information on the ductility of the buildings, even though the related capacity margin is not expressed as a deformation capacity. Analogously, the other margin ratios (e.g., $Z_{\theta u}^{I D R u 5}$ ) supply information on the post-elastic and softening properties and capacities of the buildings, also expressed as a function of the building typology. The relatively higher (lower) inelastic capacity of BF (PF) building is quantitatively confirmed by larger (lower) $Z_{X}^{I D R u 5}$ ratios. BF $Z_{\theta y}^{I D R u 5}$ is approximately the double and triple of IF $Z_{\theta y}^{I D R u 5}$ and $\mathrm{PF} Z_{\theta y}^{I D R u 5}$, respectively, and this latter was equal to about 5.4. BF $Z_{R D R u 1}^{I D R u 5}$ is slightly larger than PF $Z_{R D R u 1}^{I D R u 5}$, whereas IF $Z_{R D R u 1}^{I D R u} 5$ is 2.5 and 1.9 times larger than PF $Z_{R D R u 1}^{I D R u}$ and $\mathrm{BF}$ $Z_{R D R u 1}^{I D R u}$, respectively. $Z_{R D R u 2}^{I D R u}$ is relatively similar among the different building typologies, and IF (BF) exhibit the lowest (highest) value, equal to 1.10 (1.43); PF exhibits an intermediate value (1.23). PF $Z_{I D R M 1}^{I D R u 5}$ is quite similar to $\mathrm{BF}$ one, whereas IF $Z_{I D R u 1}^{I D R}$ is significantly larger than $\mathrm{BF}$ and PF $Z_{I D R u 1}^{I D R 45}$; PF $Z_{\text {IDR R } 52}^{I D R}, Z_{I D R u 3}^{I D R}$, and $Z_{I D R u 4}^{I D R 2}$ values are quite similar to IF ones, and smaller than $\mathrm{BF}$ ones. $Z_{\theta u}^{I D K 5}$ ratios related to $\mathrm{BF}(\mathrm{PF})$ range within 2 and 3 (1 and 2 ), and this stresses the high (low) local to global collapse capacity related to BF (PF). IF $Z_{\theta u}^{I D R 5}$ is intermediate between the other building typologies.

$\mathrm{Z}_{X}^{Y}$ was also evaluated considering the following inter-capacity margin ratios related to AQ site buildings (Fig. 14): $\theta_{u 1}$ to $\mathrm{RDR}_{\mathrm{u} 1}, \theta_{u 1}$ to $\mathrm{RDR}_{\mathrm{u} 2}, \mathrm{RDR}_{\mathrm{u} 1}$ to $\mathrm{RDR}_{\mathrm{u} 2}, \theta_{u 1}$ to $\mathrm{IDR}_{\mathrm{u} 4}$, $\theta_{y}$ to $\mathrm{RDR}_{\mathrm{u} 1}$, and $\theta_{y}$ to $\mathrm{IDR}_{\mathrm{u} 1}$. $\theta_{u 1}$ was chosen to represent the rotational collapse capacity since this formulation typically represents the most used criterion among the investigated ones. The margin between $\mathrm{RDR}_{\mathrm{u} 2}$ and $\theta_{u 1}$ is larger than the margin between $\mathrm{RDR}_{\mathrm{u} 1}$ and $\theta_{u l}$, proving that $\mathrm{RDR}_{\mathrm{u} 1}$ is more consistent with the local criterion; for IF building, the margin

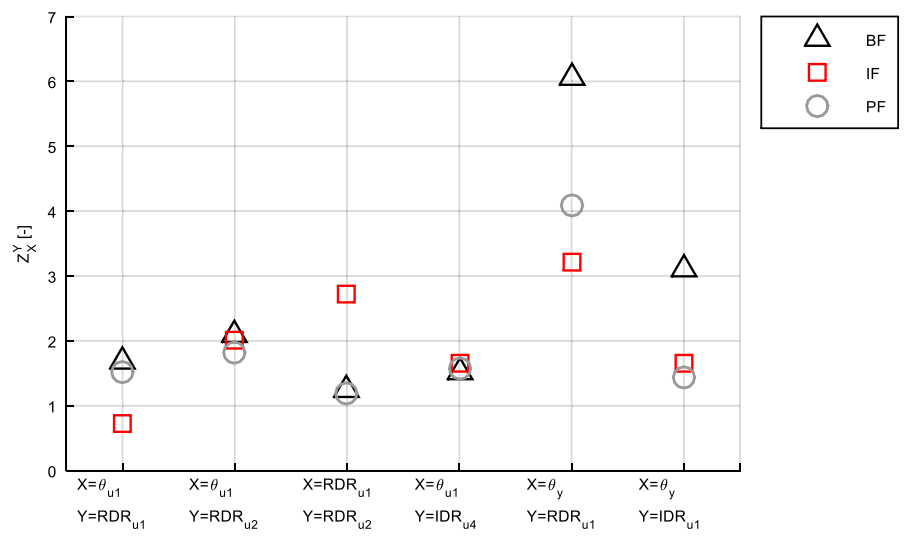

Fig. 14 Inter-capacity margin $\operatorname{ratios} Z_{X}^{Y}$ related to AQ site buildings 
to $\theta_{u 1}$ is lower than one, showing that unexpectedly $\mathrm{RDR}_{\mathrm{u} 1}$ condition precedes the local collapse, as already revealed by Fig. 11 . The $\theta_{u 1}$ to $\mathrm{IDR}_{\mathrm{u} 4}$ margin ratio does not depend on the building type and has a value which is not extremely large (e.g., smaller than the $\theta_{u 1}$ to $\mathrm{RDR}_{\mathrm{u} 2}$ margin ratio). A significant margin ratio is found regarding yielding limit, if $\mathrm{RDR}_{\mathrm{u} 1}$ is considered, especially for $\mathrm{BF}$ building, whereas the yielding limit margin is smaller if $\mathrm{IDR}_{\mathrm{u} 1}$ is considered, especially for both IF and PF buildings.

\section{Key findings and research implications}

The key findings resulting from the collapse characterization are summarized and discussed in the following according to the most relevant aspects.

\subsection{Yielding limit}

The buildings exhibit (local) yielding limit $\left(\theta_{y}\right)$ in almost all cases (e.g., very high probability over different records) under the seismic demand related to the collapse condition. This confirms a consistency with one of the main objectives of the capacity design approach. $\mathrm{IDR}_{\mathrm{u} 1}$ was found to be compatible with the building yielding onset for both infilled typologies, with the $\mathrm{IDR}_{\mathrm{u} 1}$ exhibiting a slightly lower fragility than $\theta_{y}$. This does not occur for bare frame buildings, where $\mathrm{IDR}_{\mathrm{u} 1}$ corresponds to a fragility significantly lower than $\theta_{y}$. $\mathrm{IDR}_{\mathrm{u} 1}$ criterion is confirmed to be extremely conservative as a collapse criterion.

\subsection{Chord rotation collapse}

The frame elements typically exhibit less collapses if compared to the stairwell elements. For both frame and stairwell elements, even though the beam-to-column capacity design brings to the development of the plastic hinges of the beams before than the column ones, the collapse of the two types of elements is generally contemporaneous.

\section{$6.3 \theta_{u}$ capacity criteria}

The new Eurocode draft capacity in terms of empirical ultimate rotation $\left(\theta_{u 3}\right)$ produces capacities quite similar to the empirical formulation reported in the current Eurocode $\left(\theta_{u 1}\right)$, with $\theta_{u 3}$ slightly smaller than $\theta_{u 1}$ in some cases. This results in very similar fragility curves and collapse margin ratios/probabilities, with $\theta_{u 3}$ resulting in slightly higher vulnerability. The physical formulation $\left(\theta_{u 2}\right)$ and the Haselton and Deierlein (HD) capacity $\left(\theta_{u 4}\right)$ often produce capacities larger than the empirical ones $\left(\theta_{u 1}\right.$ and $\left.\theta_{u 3}\right)$. In particular, $\theta_{u 2}$ can be considerably larger than $\theta_{u 1}$ and $\theta_{u 3}$ for element sections that present a significant ultimate curvature. The fragility (collapse margin ratios) related to $\theta_{u 2}$ are moderately lower (moderately higher) than $\theta_{u 1}$ and $\theta_{u 3}$ ones, whereas the fragility (collapse margin ratios) related to $\theta_{u 4}$ are significantly lower (significantly higher) than $\theta_{u 1}$ and $\theta_{u 3}$ ones. The results confirm that the investigated empirical chord rotation formulations can be preferred to the alternative ones (e.g., physical-based) since they are moderately more conservative. As a matter of fact, the draft of the new Eurocode specifies that the physical formulation should be used in very peculiar cases, and that the empirical formulation should be used for ordinary cases (e.g., rectangular sections). In these regards, this might represent a downgrade 
of the physical formulation, which is considered to be alternative to the empirical one by the current version of the Eurocode.

The capacity margin ratios identified between the local collapse (e.g., considering the earliest $\theta_{u 1}$ achievement) and heavy plastic and significantly degraded response (e.g., $\mathrm{RDR}_{\mathrm{u} 1}$ and $\mathrm{RDR}_{\mathrm{u} 2}$, respectively) is not significantly large (e.g., not larger than two). The margin ratio does not significantly depend on the building type for $\mathrm{RDR}_{\mathrm{u} 2}$, whereas it is lower (higher) for IF (BF and PF) considering $\mathrm{RDR}_{\mathrm{u} 1}$. It is recalled that this margin could be considered to be an index of irregularity of the building inelastic response, and the implication is that this irregularity is not considerably high and that it does not significantly depend on the building typology.

\subsection{IDR us $_{\mathrm{u}}$ capacity criterion}

$\mathrm{IDR}_{\mathrm{u} 5}$ was confirmed to be consistent with heavy plastic incursions and significant degradation and compatible with critical deformations of the building, towards a sidesway-like collapse. As a matter of fact, this latter criterion determines the lowest fragility, which is significantly (slightly) lower than $\mathrm{RDR}_{\mathrm{u} 2}$ for $\mathrm{BF}$ (IF and PF) buildings. It is recalled that this latter criterion was associated with a drop of $50 \%$ of the shear strength related to the pushover curve (PO) (heavy softening). Further analyses could correlate $\mathrm{IDR}_{\mathrm{u} 5}$ to actual sidesway collapse in quantitative terms, in order to corroborate the related findings.

\subsection{IDR $\mathrm{I}_{\mathrm{u} 2}$ to $\mathrm{IDR}_{\mathrm{u} 4}$ capacity criteria}

The $\mathrm{IDR}_{\mathrm{u} 2}$ to $\mathrm{IDR}_{\mathrm{u} 4}$ fragility curves are compatible with the $\theta_{u}$ ones, especially considering $\mathrm{IDR}_{\mathrm{u} 4}$ and $\theta_{u 4}$ for $\mathrm{BF} / \mathrm{PF}$ buildings. Moreover, $\mathrm{IDR}_{\mathrm{u} 4}$ is also relatively far from $\mathrm{RDR}_{\mathrm{u} 2}$ and $\mathrm{IDR}_{\mathrm{u} 5}$ curves. Therefore, $\mathrm{IDR}_{\mathrm{u} 4}$ can be considered to be consistent with a condition of incursion into the plastic response that is still early if compared to heavy inelastic global response and sidesway-like collapse. This characteristic is not affected by the different building typologies, and this condition expresses the robustness of the criterion. Therefore, $\mathrm{IDR}_{\mathrm{u} 4}$ criterion might be used for reliable expeditious assessment of collapse since the quick and less accurate criterion evaluation (fixed threshold) is balanced by a higher safety.

\subsection{Inter-capacity margin ratios}

The inelastic capacities of the investigated buildings can be expressed as a function of the estimated inter-capacity margin ratios. For example, the higher and lower inelastic performance of $\mathrm{BF}$ and PF buildings is overall expressed by larger and lower $Z_{X}^{I D R u 5}$, respectively. Analogously, the other characteristic of the local to global response and yielding to heavily plastic behavior can be assessed by considering the provided inter-capacity ratios.

\subsection{Design safety}

Considering $\mathrm{IDR}_{\mathrm{u} 5}$ as a capacity criterion, the collapse margin ratios are significantly higher and slightly higher than the target values considering BF and PF buildings, respectively, and IF buildings have intermediate trend. Therefore, the design prescriptions produce excessively conservative and just safe responses regarding BF and PF buildings, respectively, with intermediate over-safety conditions regarding IF buildings. It is worth to 
recall that the identified trends are related to AQ site buildings, which are designed considering the highest seismic hazard in Italy.

\section{Conclusions}

The paper investigated several capacity criteria — some of them never investigated - for the assessment of the collapse of low-rise RC frame buildings. In particular, bare frame (BF), infilled frame (IF), and pilotis frame (PF) buildings were designed according to the Italian building code considering low-to-high seismicity sites in Italy. The collapse capacity was assessed by considering both local and global collapse criteria, which were derived from literature studies and codes. The seismic demand was assessed by nonlinear multiple-stripe analysis (MSA) by considering modeling of both frame elements and infills. The collapse characterization was conducted according to the performance-based earthquake engineering (PBEE) approach. Collapse demand to capacity ratios were computed, and fragility curves were evaluated. The collapse margin ratios/probabilities were estimated, and their comparison with target (or acceptable) values allowed assessing the collapse performance according to the different criteria. Finally, the margin identified among the investigated criteria results (inter-capacity margin ratios) were evaluated.

The paper supplied novel information and technical insights into the collapse of low-rise code-conforming buildings, focusing on the influence of the different capacity criteria on the building collapse features. In particular, quantitative information was supplied on the building yielding and inelastic capacities and on the collapse performance according to the different criteria. In the light of the results, the use of consistent capacity criteria was discussed and safety and economic considerations regarding the design process were outlined.

The study cannot be considered to be exhaustive despite the extensive and wide numerical analyses and the robust assessment methodologies. It should be stressed that the quantitative findings might reflect the fact the low-rise buildings were considered in the study. However, the methodology can be fully extended to different building types and soil conditions, and the trends of the findings could also be found with regard to different case studies and applications. Finally, further analyses should be performed by refining the numerical modeling (e.g., including beam-to-column joint response) and assessing the sidesway collapse considering a more direct approach.

Acknowledgements The support for the numerical analyses provided by Dr. C. Petrone and Eng. F. Napoletano is fully acknowledged.

Authors' contributions GM provided the research funding; GM and DD conceived the study; FC, DD, and GM developed the models and carried out the numerical simulations; DD processed the data and elaborated the results; DD wrote the draft; GM and EC revised and finalized the manuscript.

Funding Open access funding provided by Università degli Studi di Napoli Federico II within the CRUICARE Agreement. The research study presented in this paper was funded by the Italian Department of Civil Protection in the framework of the national project DPC-ReLUIS 2019-2021 "RINTC".

Data availability The data that support the findings of this study are available from the corresponding author, GM, upon reasonable request.

Code availability Due to the nature of this research, participants of this study did not agree for their code data to be shared publicly, so supporting code data are not available. 


\section{Declarations}

Conflicts of interest The authors declare no conflict of interest or competing interests.

Ethics approval Not applicable.

Consent to participate Not applicable.

Consent for publication The authors express their consent for publication of the manuscript in Bulletin of Earthquake Engineering, Springer.

Open Access This article is licensed under a Creative Commons Attribution 4.0 International License, which permits use, sharing, adaptation, distribution and reproduction in any medium or format, as long as you give appropriate credit to the original author(s) and the source, provide a link to the Creative Commons licence, and indicate if changes were made. The images or other third party material in this article are included in the article's Creative Commons licence, unless indicated otherwise in a credit line to the material. If material is not included in the article's Creative Commons licence and your intended use is not permitted by statutory regulation or exceeds the permitted use, you will need to obtain permission directly from the copyright holder. To view a copy of this licence, visit http://creativecommons.org/licenses/by/4.0/.

\section{References}

American Society of Civil Engineers (2017a) Seismic evaluation and retrofit of existing buildings, 41st edn. American Society of Civil Engineers, Reston, VA

American Society of Civil Engineers (ed) (2017b) ASCE 7-16. Minimum design loads for buildings and other structures. American Society of Civil Engineers: Structural Engineering Institute, Reston, VA

Ansal A (2014) Perspectives on European earthquake engineering and seismology, vol 1. Springer, Berlin

Baker JW (2015) Efficient analytical fragility function fitting using dynamic structural analysis. Earthq Spectra 31:579-599. https://doi.org/10.1193/021113EQS025M

Baradaran Shoraka M, Yang TY, Elwood KJ (2013) Seismic loss estimation of non-ductile reinforced concrete buildings. Earthq Eng Struct Dyn 42:297-310. https://doi.org/10.1002/eqe.2213

Bertoldi SH, Decanini LD, Gavarini C (1993) Telai tamponati soggetti ad azioni sismiche, un modello semplifcato: confronto sperimentale e numerico (in Italian). In: Atti del VI convegno nazionale ANIDIS. Perugia, pp 815-824

Beverly P, International Federation for Structural Concrete (eds) (2013) fib model code for concrete structures 2010. Ernst \& Sohn, Berlin

Biskinis D, Fardis MN (2010a) Deformations at flexural yielding of members with continuous or lap-spliced bars. Struct Concr 11:127-138. https://doi.org/10.1680/stco.2010.11.3.127

Biskinis D, Fardis MN (2010b) Flexure-controlled ultimate deformations of members with continuous or lap-spliced bars. Struct Concr 11:93-108. https://doi.org/10.1680/stco.2010.11.2.93

Borg RC (2015) The deformation capacity of reinforced concrete elements subjected to seismic loading: determination of empirical equations for assessment. Department of Civil, Environmental and Geomatic Engineering. University College London

British Standards Institution, European Committee for Standardization (2005) Eurocode 8, design of structures for earthquake resistance. British Standards Institution, London

Camata G, Celano F, De Risi MT et al (2017) Rintc project: nonlinear dynamic analyses of Italian codeconforming reinforced concrete buildings for risk of collapse assessment. In: Proceedings of the 6th international conference on computational methods in structural dynamics and earthquake engineering (COMPDYN 2015). Institute of Structural Analysis and Antiseismic Research School of Civil Engineering National Technical University of Athens (NTUA) Greece, Rhodes Island, Greece, pp 1474-1485

Cardone D, Perrone G (2015) Developing fragility curves and loss functions for masonry infill walls. Earthq Struct 9:257-279. https://doi.org/10.12989/EAS.2015.9.1.257

CEN (2005) EN 1998-3. Eurocode 8: design of structures for earthquake resistance-part 3: assessment and retrofitting of buildings 
CEN (2020) Draft of new EN 1998-3. Eurocode 8: design of structures for earthquake resistance-part 3: assessment and retrofitting of buildings

CEN (2004) EN 1992-1-1. Eurocode 2: design of concrete structures-part 1-1: general rules and rules for buildings

Charney FA (2008) Unintended consequences of modeling damping in structures. J Struct Eng 134:581592. https://doi.org/10.1061/(ASCE)0733-9445(2008)134:4(581)

Cimmino M, Magliulo G, Manfredi G (2020) Seismic collapse assessment of new European singlestory RC precast buildings with weak connections. Bull Earthq Eng. https://doi.org/10.1007/ s10518-020-00952-7

Cremen G, Baker JW (2019) Improving FEMA P-58 non-structural component fragility functions and loss predictions. Bull Earthq Eng 17:1941-1960. https://doi.org/10.1007/s10518-018-00535-7

CSA (2014) CSA A23.3-14. Canadian Standards association design of concrete structures. CSA, Mississauga, ON, Canada

CS.LL.PP. (2018) D.M. del 17/01/2018 - “Aggiornamento delle Norme tecniche per le Costruzioni 2018” NTC 2018 (in Italian)

CS.LL.PP. (2008) D.M. del 14/01/2008 - “Norme tecniche per le Costruzioni 2008”. NTC 2008 (in Italian)

Decanini L, Mollaioli F, Mura A, Saragoni R (2004) Seismic performance of masonry infilled R/C frames. Vancouver, British Columbia, Canada

Decanini LD, Fantin GE (1986) Modelos simplificados de la mampostería incluidas en porticos. Características de rigidez y resistencia lateral en estado límite (in Spanish). In: Actas de las VI Jornadas Argentinas de Ingenieria Estructura. Buenos Aires, Argentina, pp 817-836

Decanini LD, Liberatore L, Mollaioli F (2014) Strength and stiffness reduction factors for infilled frames with openings. Earthq Eng Eng Vib 13:437-454. https://doi.org/10.1007/s11803-014-0254-9

Deniz D, Song J, Hajjar JF (2017) Energy-based seismic collapse criterion for ductile planar structural frames. Eng Struct 141:1-13. https://doi.org/10.1016/j.engstruct.2017.02.051

Di Sarno L, Magliulo G, D’Angela D, Cosenza E (2019) Experimental assessment of the seismic performance of hospital cabinets using shake table testing. Earthq Eng Struct Dyn 48:103-123. https:// doi.org/10.1002/eqe.3127

Di Trapani F, Bolis V, Basone F, Preti M (2020) Seismic reliability and loss assessment of RC frame structures with traditional and innovative masonry infills. Eng Struct 208:110306. https://doi.org/ 10.1016/j.engstruct.2020.110306

Douglas J, Gkimprixis A (2018) Risk targeting in seismic design codes: the state of the art, outstanding issues and possible paths forward. In: Vacareanu R, Ionescu C (eds) Seismic hazard and risk assessment. Springer, Cham, pp 211-223

Ercolino M, Bellotti D, Magliulo G, Nascimbene R (2018) Vulnerability analysis of industrial RC precast buildings designed according to modern seismic codes. Eng Struct 158:67-78. https://doi.org/ 10.1016/j.engstruct.2017.12.005

Fajfar P (2018) Analysis in seismic provisions for buildings: past, present and future: the fifth Prof. Nicholas Ambraseys Lecture. Bull Earthq Eng 16:2567-2608. https://doi.org/10.1007/ s10518-017-0290-8

Fardis MN (2013) Performance- and displacement-based seismic design and assessment of concrete structures in fib Model Code 2010. Struct Concr 14:215-229. https://doi.org/10.1002/suco.201300001

Fardis MN, Biskinis D (2003) Deformation capacity of RC members, as controlled by flexure or shear. In: Otani symposium, pp 511-530

Federal Emergency Management Agency (FEMA) (2009) Quantification of building seismic performance factors. Report No. P695. Washington D.C., USA

Federal Emergency Management Agency (FEMA) (1997) NEHRP guidelines for the seismic rehabilitation of buildings. FEMA 273

Federal Emergency Management Agency (FEMA) (ed) (2000) FEMA 356 Prestandard and commentary for the seismic rehabilitation of buildings

Fusco R, Montuori R, Nastri E, Piluso V (2018) Critical analysis of ultimate rotation formula for R.C. columns subjected to cyclic loadings. Eng Struct 177:160-174. https://doi.org/10.1016/j.engstruct. 2018.09.065

Ghannoum WM, Matamoros AB (2014) Nonlinear modeling parameters and acceptance criteria for concrete columns. In: ACI Symp Publ, p 297

Ghannoum WM, Sivaramakrishnan B (2012) ACI 369 rectangular column database

Ghobarah A (2004) On drift limits associated with different damage levels. In: Proceedings of international workshop on performance-based seismic design. Department of Civil Engineering, McMaster University, Bled (Slovenia) 
Gokkaya BU, Baker JW, Deierlein GG (2016) Quantifying the impacts of modeling uncertainties on the seismic drift demands and collapse risk of buildings with implications on seismic design checks. Earthq Eng Struct Dyn 45:1661-1683. https://doi.org/10.1002/eqe.2740

Goulet CA, Haselton CB, Mitrani-Reiser J et al (2007) Evaluation of the seismic performance of a codeconforming reinforced-concrete frame building-from seismic hazard to collapse safety and economic losses. Earthq Eng Struct Dyn 36:1973-1997. https://doi.org/10.1002/eqe.694

Haselton CB, Baker JW, Stewart JP et al (2017) Response history analysis for the design of new buildings in the NEHRP provisions and ASCE/SEI 7 standard: part I-overview and specification of ground motions. Earthq Spectra 33:373-395. https://doi.org/10.1193/032114EQS039M

Haselton CB, Deierlein GG (2007) Assessing seismic collapse safety of modern reinforced concrete moment frame buildings. The John A. Blume Earthquake Engineering Center. Department of Civil and Environmental engineering. Stanford University, Stanford CA

Haselton CB, Liel AB, Deierlein GG (2009) Simulating structural collapse due to earthquakes: model idealization, model calibration, and numerical solution algorithms. In: COMPDYN 2009 ECCOMAS thematic conference on computational methods in structural dynamics and earthquake engineering. Rhodes, Greece

Haselton CB, Liel AB, Deierlein GG et al (2011) Seismic collapse safety of reinforced concrete buildings. I: Assessment of ductile moment frames. J Struct Eng 137:481-491. https://doi.org/10.1061/(ASCE)ST. 1943-541X.0000318

Haselton CB, Liel AB, Taylor-Lange S, Deierlein GG (2008) PEER Report No. 2007/03. Beam-column element model calibrated for predicting flexural response leading to global collapse of RC frame buildings. Pacific Earthquake Engineering Research Center, University of California, Berkeley, CA

Ibarra LF, Krawinkler H (2005) Global collapse of frame structures under seismic excitations. The John A. Blume Earthquake Engineering Center. Department of Civil and Environmental engineering. Stanford University, Stanford CA

Ibarra LF, Medina RA, Krawinkler H (2005) Hysteretic models that incorporate strength and stiffness deterioration. Earthq Eng Struct Dyn 34:1489-1511. https://doi.org/10.1002/eqe.495

Iervolino I, Spillatura A, Bazzurro P (2018) Seismic reliability of code-conforming Italian buildings. J Earthq Eng 22:5-27. https://doi.org/10.1080/13632469.2018.1540372

Iervolino I, Spillatura A, Bazzurro P (2017) Rintc project-assessing the (Implicit) seismic risk of codeconforming structures In Italy. In: Proceedings of the 6th international conference on computational methods in structural dynamics and earthquake engineering (COMPDYN 2015). Institute of Structural Analysis and Antiseismic Research School of Civil Engineering National Technical University of Athens (NTUA) Greece, Rhodes Island, Greece, pp 1545-1557

Jalayer F (2003) Direct probabilistic seismic analysis: implementing nonlinear dynamic assessment. PhD thesis, Department of Civil and Environmental Engineering, Stanford University

Jayaram N, Lin T, Baker JW (2011) A computationally efficient ground-motion selection algorithm for matching a target response spectrum mean and variance. Earthq Spectra 27:797-815. https://doi.org/ 10.1193/1.3608002

Karavasilis TL, Ricles JM, Sause R (2009) Implementation of deterioration elements in OpenSEES for collapse simulations. ATLSS Engineering Research Center

Lignos DG, Krawinkler H, Whittaker AS (2011) Prediction and validation of sidesway collapse of two scale models of a 4-story steel moment frame. Earthq Eng Struct Dyn 40:807-825. https://doi.org/10.1002/ eqe. 1061

Lin T, Haselton CB, Baker JW (2013) Conditional spectrum-based ground motion selection. Part I: hazard consistency for risk-based assessments: conditional spectrum-based ground motion selection-I. Earthq Eng Struct Dyn 42:1847-1865. https://doi.org/10.1002/eqe.2301

Luco N, Ellingwood BR, Hamburger RO et al (2007) Risk-targeted versus current seismic design maps for the conterminous United States. In: SEAOC 2007 convention proceedings

Magliulo G, Bellotti D, Cimmino M, Nascimbene R (2018) Modeling and seismic response analysis of RC precast Italian Code-conforming buildings. J Earthq Eng 22:140-167. https://doi.org/10.1080/13632 469.2018.1531093

McKenna F, Fenves GL, Scott MH (2000) OpenSees: open system for earthquake engineering simulation. Pacific Earthquake Engineering Research Center. University of California,Berkeley, CA. Available at: http://opensees.berkeley.edu

Meletti C, Montaldo V (2007) Stime di pericolosità sismica per diverse probabilità di superamento in 50 anni: valori di ag. Progetto DPC-INGV S1, Deliverable D2 (in Italian). http://esse1.mi.ingv.it/d2.html

Mpampatsikos V, Nascimbene R, Petrini L (2008) A critical review of the R.C. frame existing building assessment procedure according to Eurocode 8 and Italian seismic code. J Earthq Eng 12:52-82. https://doi.org/10.1080/13632460801925020 
Mwafy AM, Elnashai AS (2001) Static pushover versus dynamic collapse analysis of RC buildings. Eng Struct 23:407-424. https://doi.org/10.1016/S0141-0296(00)00068-7

NEHRP Consultants Joint Venture (2010) NIST GCR 10-917-8. Evaluation of the FEMA P-695 methodology for quantification of building seismic performance factors. U.S. Department of Commerce Engineering Laboratory National Institute of Standards and Technology

Noh NM, Tesfamariam S (2018) Seismic collapse risk assessment of code-conforming RC moment resisting frame buildings designed with 2014 Canadian Standard Association Standard A23.3. Front Built Environ 4:53. https://doi.org/10.3389/fbuil.2018.00053

O'Reilly GJ, Sullivan TJ (2018) Probabilistic seismic assessment and retrofit considerations for Italian RC frame buildings. Bull Earthq Eng 16:1447-1485. https://doi.org/10.1007/s10518-017-0257-9

Panagiotakos TB, Fardis M (2001) Deformations of reinforced concrete members at yielding and ultimate. ACI Struct J. https://doi.org/10.14359/10181

Panagiotakos TB, Fardis MN (2004) Seismic performance of RC frames designed to Eurocode 8 or to the Greek Codes 2000. Bull Earthq Eng 2:221-259. https://doi.org/10.1007/s10518-004-2288-2

Porter K, Kennedy R, Bachman R (2006) Developing fragility functions for building components for ATC-58. A report to ATC-58. Applied Technology Council, Redwood City, CA, USA

Porter K, Kennedy R, Bachman R (2007) Creating fragility functions for performance-based earthquake engineering. Earthq Spectra 23:471-489. https://doi.org/10.1193/1.2720892

Pourreza F, Mousazadeh M, Basim MCh (2021) An efficient method for incorporating modeling uncertainties into collapse fragility of steel structures. Struct Saf 88:102009. https://doi.org/10.1016/j. strusafe.2020.102009

Presidente del Consiglio dei Ministri (2003) Ordinanza No. 3274. Primi elementi in material di criteri generali per la classificazione sismica del territorio nazionale e di normative tecniche per le costruzioni in zona sismica

Presidente del Consiglio dei Ministri (2005) Ordinanza No. 3431. Ulteriori modifiche ed integrazione all' Ordinanza del Presidente del Consiglio dei Ministri No. 3274 recante "primi elementi in material di criteri generali per la classificazione sismica del territorio nazionale e di normative tecniche per le costruzioni in zona sismica

Rajeev P, Tesfamariam S (2012) Seismic fragilities for reinforced concrete buildings with consideration of irregularities. Struct Saf 39:1-13. https://doi.org/10.1016/j.strusafe.2012.06.001

Ricci P, Manfredi V, Noto F et al (2018) Modeling and seismic response analysis of Italian code-conforming reinforced concrete buildings. J Earthq Eng 22:105-139. https://doi.org/10.1080/13632 469.2018.1527733

RINTC Workgroup (2018) Results of the 2015-2017 implicit seismic risk of code-conforming structures in Italy (RINTC) project. Rete dei Laboratori Universitari di Ingegneria Sismica (ReLUIS), Naples

Rofooei FR, Seyedkazemi A (2020) Evaluation of the seismic performance factors for steel diagrid structural systems using FEMA P-695 and ATC-19 procedures. Bull Earthq Eng 18:4873-4910. https://doi.org/10.1007/s10518-020-00876-2

Rossetto T, Elnashai A (2005) A new analytical procedure for the derivation of displacement-based vulnerability curves for populations of RC structures. Eng Struct 27:397-409. https://doi.org/10. 1016/j. engstruct.2004.11.002

Sassun K, Sullivan TJ, Morandi P, Cardone D (2016) Characterising the in-plane seismic performance of infill masonry. Bull N Z Soc Earthq Eng 49:98-115. https://doi.org/10.5459/bnzsee.49.1.98-115

Scozzese F, Tubaldi E, Dall'Asta A, (2020) Assessment of the effectiveness of multiple-stripe analysis by using a stochastic earthquake input model. Bull Earthq Eng 18:3167-3203. https://doi.org/10. 1007/s10518-020-00815-1

Shafei B, Zareian F, Lignos DG (2011) A simplified method for collapse capacity assessment of moment-resisting frame and shear wall structural systems. Eng Struct 33:1107-1116. https://doi. org/10.1016/j.engstruct.2010.12.028

Shahnazaryan D, O'Reilly GJ (2021) Integrating expected loss and collapse risk in performance-based seismic design of structures. Bull Earthq Eng. https://doi.org/10.1007/s10518-020-01003-x

Smith BS (1962) Lateral stiffness of infilled frames. J Struct Div 88:183-226

Structural Engineers Association Of California (SEAOC) (1995) Vision 2000 Report. Performance based seismic engineering of buildings

Suita K, Yamada S, Tada M et al (2008) Results of recent E-Defense tests on full-scale steel buildings: part 1-collapse experiments on 4-story moment frames. In: Structures congress 2008. American Society of Civil Engineers, Vancouver, British Columbia, Canada, pp 1-10

Suzuki A, Iervolino I (2019) Seismic fragility of code-conforming italian buildings based on SDoF approximation. J Earthq Eng. https://doi.org/10.1080/13632469.2019.1657989 
Terrenzi M, Spacone E, Camata G (2018) Collapse limit state definition for seismic assessment of code-conforming RC buildings. Int J Adv Struct Eng 10:325-337. https://doi.org/10.1007/ s40091-018-0200-6

Terrenzi M, Spacone E, Camata G (2019) Engineering demand parameters for the definition of collapse in code conforming Rc buildings. In: Proceedings of the 7th international conference on computational methods in structural dynamics and earthquake engineering (COMPDYN 2015). Institute of Structural Analysis and Antiseismic Research School of Civil Engineering National Technical University of Athens (NTUA) Greece, Crete, Greece, pp 2756-2768

Vamvatsikos D, Cornell CA (2002) Incremental dynamic analysis. Earthq Eng Struct Dyn 31:491-514. https://doi.org/10.1002/eqe.141

Vamvatsikos D, Jalayer F, Cornell CA (2003) Application of incremental dynamic analysis to an RC- Structure. In: Proceedings of the FIB symposium on concrete structures in seismic regions

Verderame GM, Ricci P (2018) An empirical approach for nonlinear modelling and deformation capacity assessment of RC columns with plain bars. Eng Struct 176:539-554. https://doi.org/10.1016/j.engst ruct.2018.09.022

Verderame GM, Ricci P, De Risi MT, Del Gaudio C (2019) Experimental assessment and numerical modelling of conforming and non-conforming RC frames with and without infills. J Earthq Eng. https://doi. org/10.1080/13632469.2019.1692098

Zhang Y, He Z (2020) Acceptable values of collapse margin ratio with different confidence levels. Struct Saf 84:101938. https://doi.org/10.1016/j.strusafe.2020.101938

Publisher's Note Springer Nature remains neutral with regard to jurisdictional claims in published maps and institutional affiliations. 


\section{Authors and Affiliations}

\section{Danilo D'Angela $^{1}$ (D) Gennaro Magliulo ${ }^{1,2}$ (D) $\cdot$ Francesca Celano $^{3}$ (D) Edoardo Cosenza $^{1,2}$ (D)}

Danilo D'Angela

danilo.dangela@unina.it

Francesca Celano

Francesca.Celano@ikpir.fgg.uni-lj.si

Edoardo Cosenza

cosenza@unina.it

1 Department of Structures for Engineering and Architecture, University of Naples Federico II, Via Claudio 21, 80125 Naples, Italy

2 Construction Technologies Institute, National Research Council, University of Naples Federico II, Via Claudio 21, 80125 Naples, Italy

3 Faculty of Civil and Geodetic Engineering, University of Ljubljana, Jamova 2, 1000 Ljubljana, Slovenia 